\title{
Optimization of extraction conditions and determination of purine content in marine fish during boiling
}

\author{
Tingting Li ${ }^{1}$, Likun Ren ${ }^{2}$, Dangfeng Wang ${ }^{2}$, Minjie Song ${ }^{2}$, Qiuying $\mathbf{L i}^{2}{ }^{2}$, Jianrong $\mathbf{L i}^{\text {Corresp. }}{ }^{2}$ \\ 1 Department of Life Science, Dalian Minzu University, Dalian, Chian \\ 2 College of Food Science and Technology, Bohai University, Jinzhou, Chian \\ Corresponding Author: Jianrong Li \\ Email address: jwltt@dlnu.edu.cn
}

\begin{abstract}
Background. Gout is the second most common metabolic disease affecting human health. The disease of gout is closely related to the level of uric acid, which is the end-product of human purine metabolism. Moreover, food is the main way of external ingestion of purine.
\end{abstract}

Method. A simple and time-saving method was developed to extract purines like adenine, hypoxanthine, guanine, and xanthine from marine fish by single factor design combined with Box- Behnken. The contents of these purines in the edible parts and internal organs of marine fish, as well as Scophthalmus maximus, were determined by HPLC to investigate the relationship between the boiling process and purine content.

Result. The mixed-acid method was chosen for the extraction of purine bases and the extraction conditions were as follows: mixture acid $90.00 \%$ TFA/80.00\% FA (v/v, 1:1); hydrolysis temperature $90.00^{\circ} \mathrm{C}$; time $10.00 \mathrm{~min}$; liquid-to-solid ratio 30:1. The total purine content of the edible parts (eyes, dorsal muscles, abdominal muscles, and skin) was the highest in Scophthalmus maximus, followed by sphyraena, Sardinella, Trichiurus lepturus, Scomberomorus niphonius, Pleuronectiformes, sea catfish, Anguillidae, and Rajiformes. Moreover, boiling significantly reduced the purine content in the marine fish because of the transfer of the purines to the cooking liquid during boiling. Scophthalmus maximus, Sphyraena and Sardinella were regard as high-purine marine fish, which we should eat less. We also confirmed that boiling significantly transferred purine bases from fish to cooking liquid. Thus, boiling could reduce the purine content of fish, thereby reducing the risk of hyperuricemia and gout. 
1 Optimization of extraction conditions and determination of purine content in marine fish

2 during boiling

3 Tingting Li' ${ }^{1}$, Likun Ren², Dangfeng Wang ${ }^{2}$, Minjie Song², Qiuying Li ${ }^{2}$, Jianrong Li ${ }^{2 *}$

$4{ }^{1}$ Department of Life Science, Dalian Minzu University, Dalian, Liaoning, China

52 College of Food Science and Technology, Bohai University, Jinzhou, Liaoning, China

6

7

8

9

10

11

12

13

16 Corresponding Author:

17 Jianrong Li

18 19, Keji Rd., New Songshan District, Jinzhou City, Liaoning Province, 121013, China

19 Email address: lijr6491@163.com 
Abstract

Background. Gout is the second most common metabolic disease affecting human health. The disease of gout is closely related to the level of uric acid, which is the end-product of human purine metabolism. Moreover, food is the main way of external ingestion of purine.

Method. A simple and time-saving method was developed to extract purines like adenine, hypoxanthine, guanine, and xanthine from marine fish by single factor design combined with Box- Behnken. The contents of these purines in the edible parts and internal organs of marine fish, as well as Scophthalmus maximus, were determined by HPLC to investigate the relationship between the boiling process and purine content.

Result. The mixed-acid method was chosen for the extraction of purine bases and the extraction conditions were as follows: mixture acid 90.00\% TFA/80.00\% FA (v/v, 1:1); hydrolysis temperature $90.00^{\circ} \mathrm{C}$; time $10.00 \mathrm{~min}$; liquid-to-solid ratio $30: 1$. The total purine content of the 
gout.

\section{Introduction}

Gout is a type of inflammatory arthritis caused by the deposition of monosodium crystals in tissues. It has become the second-most common metabolic disease affecting human health (Goldberg et al., 2017). According to statistics, about 75 million people in China now suffer from gout or hyperuricemia. These diseases are strongly influenced by uric acid, which is a metabolite of the purine components of RNA and DNA present in foods. Normal serum urate levels in healthy adults are below $0.45 \mathrm{mmol} / \mathrm{L}$ for men and below $0.36 \mathrm{mmol} / \mathrm{L}$ for women (Zhao et al., 2005). However, when the blood uric acid exceeds normal levels, there is an increased risk for diseases such as gout.

Diet is a key factor in high serum urate levels, and some studies have confirmed that a lowpurine diet significantly helps patients with hyperuricemia and gout (Lou, Lin \& Benkmann, 2001; Shmerling, 2012). The consumption of food with high purine content can disrupt the balance between uric acid synthesis and metabolism, leading to hyperuricemia or eventual gout (Gowda et al., 2010). Therefore, adherence to a low-purine diet plays an important role in reducing serum uric acid concentration in humans (Suresh \& Das, 2012). Compared with other meat products, fish is usually labeled as a healthier food because of its high nutritional value (e.g., high levels of unsaturated fatty acids). However, this nutritional advice may mislead consumers who are not aware of the intrinsic purine content of fish. The quantity and types of purine bases (adenine, guanine, hypoxanthine, and xanthine) in food, however, might be altered 
by different cooking methods (Brulé, Sarwar \& Savoie, 1989). Previous studies have shown that various processing methods can reduce the purine contents in foodstuff. Lou (2001) evaluated the effects of processing on reducing purines contents in tilapia, with three cooking treatments (boiling, steaming and microwave cooking) were carried out. The results showed that the content of adenine and hypoxanthine decreased $46.40 \%$ during boiling, which achieved the highest ratio of purine removal. And the effects of cooking on purine concentration in beef and chicken has also been widely studied, but little information is available on the purine content in the edible parts of other marine fish. There are many methods for simultaneous quantification of the purine levels in food. Klampfl, Himmelsbach, Buchberger, and Klein (2002) analyzed the purine and pyrimidine contents in beer by capillary zone electrophoresis. Similarly, an ultra-highperformance liquid chromatography-tandem mass spectrometry (UPLC-MS/MS) method was used to analyze seven purines and pyrimidines in pork products (Clariana et al., 2010). Highperformance liquid chromatography (HPLC) has become the most widely used method for purine detection because of its high efficiency, convenience, and accuracy (Rong et al., 2015). Other studies have investigated the purine contents of vegetarian meat analogues, beer, beer-like alcoholic beverages, pork, and beef via HPLC (Jaroslav et al., 2010; Fukuuchi et al, 2013; Rong et al, 2015). Nevertheless, few HPLC methods have been used to quantify the adenine, guanine, hypoxanthine, and xanthine contents in marine fish (Qu et al., 2016).

In this paper, a simple and reliable method for purine extraction is reported. Furthermore, the purine contents (adenine, guanine, hypoxanthine, and xanthine) in the edible parts of nine 
marine fish were measured by HPLC. Finally, the effect of boiling on the purine content in the edible parts of marine fish was investigated in the context of its viability in decreasing the risk of gout attacks caused by diet.

\section{Material and methods}

Chemicals and reagents

Purine standards (adenine, guanine, hypoxanthine, and xanthine) were purchased from Shanghai Aladdin Bio-Chem Technology Co., Ltd (Shanghai, China). The standards were all chromatography-grade with purity $>98 \%$. Chromatography-grade glacial acetic acid, methyl alcohol, tetrabutylammonium hydroxide, and trifluoroacetic acid (TFA) were also obtained from Shanghai Aladdin Bio-Chem Technology Co., Ltd. Analytically pure formic acid (FA) and perchloric acid (PCA) were purchased from Tianjin Fengchuan Chemical Reagent Co., Ltd (Tianjin, China). Water was purified by a Milli-Q system (Millipore, USA).

\section{Sampling and pretreatment}

Sample collection

Live marine fish (Scophthalmus maximus, Scomberomorus niphonius, Trichiurus lepturus, Pleuronectiformes, Sea catfish, Sardinella, Sphyraena, Anguillidae, and Rajiformes) were purchased from the local wholesale seafood market in Jinzhou, China, transported to the laboratory where they were killed, and then the dorsal muscles, abdominal muscles, skin, eyes, 
and viscera were removed for testing. All samples were minced and stored at $0{ }^{\circ} \mathrm{C}$ before proceeding.

\section{Sample pretreatment}

The edible parts of the marine fish (dorsal muscles, abdominal muscles, and skin) were separately boiled in water for 3, 6, 9, 12, and $15 \mathrm{~min}$, and the contents of the purine bases in all samples (edible parts and cooking liquids) were determined. The uncooked samples were used as a control group. Three independent measurements were taken, and the mean and standard deviations were calculated.

Establishment of purine extraction method

The purine bases in the samples were extracted according to the method of Piñeiro-Sotelo, López-Hernández, and Simal-Lozano (2002), with some modifications. First, 200 mg of sample was added to a centrifuge tube $(50 \mathrm{~mL})$ with $10 \mathrm{~mL}$ of acid, and heated at $90{ }^{\circ} \mathrm{C}$ in a water bath for $15 \mathrm{~min}$. Next, the acid hydrolysate was placed in a rotary evaporator at $75^{\circ} \mathrm{C}$ to remove the volatiles, and then redissolved in $10 \mathrm{~mL}$ of the HPLC mobile phase (water-methanol-glacial acetic acid-20\% tetrabutylammonium hydroxide ( $\mathrm{v} / \mathrm{v}=879 / 100 / 15 / 6)$. Finally, the sample was centrifuged at $8000 \mathrm{~g}$ for $10 \mathrm{~min}$ at $4{ }^{\circ} \mathrm{C}$ and filtered through a $0.22-\mu \mathrm{m}$ filter before analysis by HPLC.

Single-factor design

PCA method 
119 performed following the procedure reported by Piñeiro-Sotelo, López-Hernández, and Simal-

Lozano (2002), with some modifications. A single factor method was employed in this study.

121 Four factors were investigated which include PCA concentrations $(5,10,20,30,40,50,60,70$,

$12280,90$, and $100 \%)$, the temperature of water bath $\left(30,40,50,60,70,80\right.$, and $\left.90{ }^{\circ} \mathrm{C}\right)$, hydrolysis

123 time $(35,40,45,50,55,60,65$ and $70 \mathrm{~min})$ and liquid-solid ratio (10:1, 20:1, 30:1, 40:1, 50:1,

$12460: 1,70: 1,80: 1,90: 1)$. When one factor was studies, others were fixed in the optimum value

125 determined in this paper.

mixed-acid method

The mixed-acid method was optimized in a similar manner as the PCA method. Single factor experiments were performed to examine the influence of temperature in water bath $(30,40$, 50, 60, 70, 80, 90, and $\left.100^{\circ} \mathrm{C}\right)$, Liquid-solid (10:1, 20:1, 30:1, 40:1, 50:1, 60:1, 70:1, 80:1, 90:1), the concentration of TFA and FA $(45,50,55,60,65,70,75,80,85,90$ and 95\%) and hydrolysis time $(5,10,15,20,25,30,35,40,45,50,55$, and $60 \mathrm{~min})$ in extraction efficiency. The effect of each factor was explored by changing the factor while keeping other factors constant.

Plackett- Burman design for screening factors 
137

138

test, each variable was studied at two levels (Farrokhnia et al., 2016): low (-1) and high (+1)

which were selected from the maximum response interval of each independent variable (Table 1).

A total of 12 experimental runs were designed by the software of Design Expert-8.0.6 (Stat-Ease,

Inc., Minneapolis, MN, USA). The results of PBD were analyzed to select the most important factors, which were further optimized using BBD.

Box- Behnken design for optimizing of purine extraction method

In this study, BBD was used to find the optimum extraction conditions for obtaining the highest extraction yield of total purine. Based on single-factor design and PBD, level ranges of factors and critical factors were determined and selected for response surface methodological analysis. Each of these variables was studied at three different levels $(-1,0,1)$ (Grosso et al., 2014). Factors and levels of response surface methodology was shown in Table 2 . The software Design Expert 8.0.6 was used for experimental design, data analysis and model building. Threedimensional response surface plots and contour were drawn to identify the interaction between factors and responses.

\section{Validation test}

Verification experiments were performed at the predicted conditions with some modified, indicating the validity of the predicted models. When the relative error between the predicted value and the actual value was less than 5\%, it showed that the regression equation fits well with the actual situation and is accurate and reliable. 
156

157

158

159

160

161

162

163

164

165

166

167

168

169

170

171

172

173

174

175

HPLC conditions

A Shimadzu LC-2030 HPLC system (Shimadzu Corporation, Kyoto, Japan) consisting of an LC-20AD pump unit, an SPD-20AV UV detector, and a CTO-20AC column heater, was used to identify the purine bases extracted. An Agilent Eclipse XDB-C18 column $(4.6 \mathrm{~mm} \times 250.0$ $\mathrm{mm} \times 5.0 \mu \mathrm{m}$, Agilent Technologies, Germany) was used as the analytical column and maintained at $28{ }^{\circ} \mathrm{C}$ during operation. The mobile phase was water-methanol-glacial acetic acid$20 \%$ tetrabutylammonium hydroxide $(\mathrm{v} / \mathrm{v}=879 / 100 / 15 / 6, \mathrm{pH}=3.44)$, and the $10 \mu \mathrm{L}$ sample was eluted at a flow rate of $0.8 \mathrm{~mL} / \mathrm{min}$. At the end of each procedure, the analytical column was washed with the mobile phase for $30 \mathrm{~min}$ and equilibrated before the next run. The detector measured absorbance at $254 \mathrm{~nm}$ and data was analyzed using Shimadzu analysis software (Shimadzu Corporation, Kyoto, Japan).

Method evaluation

The purine base standards (adenine, guanine, hypoxanthine, and xanthine) were dissolved in ultrapure water at concentrations of $0.1,0.5,1,5,10,50,100,200$, and $300 \mathrm{mg} / \mathrm{L}$ and detected by HPLC according to the method described above. Purine bases in the samples were identified by comparing the peak retention times with those of the standard solutions. Quantification of the purine bases was based on the regression analysis of peak area against concentration. The linearity, range, squared correlation coefficient values $\left(\mathrm{R}^{2}\right)$, and limits of detection (LODs) were determined $(\mathrm{Li}, 2015)$. The LOD was calculated as the concentrations corresponding to 3 times the S/N (Peng et al., 2008). The precision of the method and the repeatability of the purine 
extraction process were evaluated by testing the mixed purine base standard solution and the extraction sample from Scophthalmus maximus (dorsal muscles) six times, and the relative standard deviation (RSD\%) was calculated. Recoveries of adenine, guanine, hypoxanthine and xanthine were determined using samples in which the content of four kinds of purines had been determined. In each case known quantities of individual purine base standards with $0.5,1,2$ times of the quantified contents was added into sample, which was then preformed to the optimum purine extraction method and then analyzed by HPLC (Jaroslav et al., 2010). And the percent recovery was calculated according to the following formula (Peng et al., 2008):

$$
\% \text { Recovery }=\frac{A-B}{C} \times 100
$$

Where $A$ is the value of purine content of the sample that added purine base standards, $B$ is the content of purine in the sample without purine base standards and $C$ is the known content of purine bases standards that added in sample.

Statistical analysis

All measurements were performed in triplicate and the standard deviation was determined using SPSS 20 for Windows (SPSS Inc., Chicago, IL, USA). Graphs were drawn with the OriginPro 8.5 software package (OriginLab, Northampton, MA, USA). Statistical significance was assessed via analysis of variance (ANOVA). Differences with $P<0.05$ were considered statistically significant.

\section{Results and discussion}


195

196

197

198

\section{HPLC method}

The HPLC method described in this paper were used to simultaneously quantify the adenine, guanine, hypoxanthine, and xanthine contents in marine fish. As shown in Fig. 1, the four purine bases were separated within $10 \mathrm{~min}$.

Establishment of the purine extraction method

Single factor design

PCA method

The results showed that acid concentration, hydrolysis temperature, hydrolysis time, and the liquid-solid ratio had influences on the extraction percent of the purines. As shown in Fig. 2, the extraction percent of the purine decreased gradually with increasing PCA concentration, eventually beginning to increase once the PCA concentration reached $60 \%$. When the concentration of PCA was $80 \%$, the extraction percent was higher. The extraction percent also reached a maximum at a hydrolysis temperature of $80^{\circ} \mathrm{C}$, beyond this point it decreased slightly. This may be due to the destruction of some purine bases at high temperatures (Jamil, Halim \& Sarbon, 2016). In addition, the extraction with the PCA method was the best with a hydrolysis time of $55 \mathrm{~min}$ and a liquid-solid ratio of 60:1. Finally, level ranges of acid concentrations (70$90 \%)$, temperatures $\left(70-90^{\circ} \mathrm{C}\right)$, hydrolysis time $(50-60 \mathrm{~min})$ and liquid-solid ratio $(50: 1-70: 1$ $\mathrm{mL} / \mathrm{g}$ ) were selected for BBD.

mixed-acid method 
purine increased firstly and then decreased with the increase of TFA concentration, with the

extraction percent reached the maximum at $85 \%$. The extraction percent of the purines fluctuated

with increasing liquid-solid ratio. And the highest extraction percent was obtained when the

sample was hydrolyzed for $10 \mathrm{~min}$. Moreover, the changes of FA concentration had little effect

on the extraction percent of purine. Finally, according to the results of single factors design, the

selected low and high values for hydrolysis temperature, liquid-solid ratio, FA concentration,

TFA concentration and hydrolysis time were $\left(80,100{ }^{\circ} \mathrm{C}\right),(20: 1,40: 1 \mathrm{~mL} / \mathrm{g}),(75,85 \%),(80,90$

$\%)$ and $(5,15 \mathrm{~min})$ in the PBD, respectively.

Plackett-Burman screening studies

The workload of a five factors response surface design was large, so its variables need to be screened. PBD was an effective method for screening the best candidate factors (Vasiee et al., 2016). Based on the result of single-factor design, a two-level Plackett-Burman design of 12 runs were inducted in this paper to confirm the important factors that significantly affect the extraction percent of mixed-acid. The standard analysis of variance (ANOVA) was calculated from experimental runs (Table 3). The analysis indicated A-hydrolysis temperature, D-TFA concentration and E-hydrolysis time had significant influence on extraction percent of purine. F- 
234 value of the model was 18.76 which indicated the model was significant. Value of $p<0.05$

235 implied this model terms were significant. Moreover, the predicted $\mathrm{R}^{2} \quad(0.7596)$ was in

236 reasonable agreement with the adjusted $\mathrm{R}^{2}(0.8898)$ as the different was $<0.2$. "Adeq precision"

237 was used as a tool to measures the signal to noise ratio, that greater than 4 was desirable. In this

238 study, a ratio of 13.549 implied an adequate signal and this model could be used to navigate the

239 design space. As shown in Table 3, the contribution of hydrolysis time $(38.76 \%)$ was the highest,

240 which was followed by hydrolysis temperature (36.42\%), TFA concentration (15.61\%), FA

241 concentration (3.04\%) and liquid to solid ratio (0.16\%). Moreover, as showed in Fig. 4, the

242 variables of $\mathrm{E}, \mathrm{A}$ and $\mathrm{D}$ presented a positive effect on the total purine extract. By analyzing the

243 data obtained from PBD, the insignificant variable was ignored and the variables of extraction

244 temperature, time and the concentration of TFA were selected for further study by BBD to attain

245 the optimal extraction process.

246 Optimization of media using Box-Behnken design

247 PCA method

248 There were a total of 29 runs for optimizing the four independent parameters in the current

249 Box-Behnken design. Table S1 shows the experimental design used for the study. The data

250 evaluated by ANOVA were presented in Table 4. These data were fitted to nonlinear quadratic

251 models for percentage yield of total purine content. The fitted model equation is:

252 Total purine yield $(\%)=85.85+0.47 \mathrm{~A}+0.063 \mathrm{~B}+0.27 \mathrm{C}-0.34 \mathrm{D}-0.085 \mathrm{AB}-0.52 \mathrm{AC}+$

$$
0.36 \mathrm{AD}+0.015 \mathrm{BC}-0.09 \mathrm{BD}+0.42 \mathrm{CD}-2.71 \mathrm{~A}^{2}-0.67 \mathrm{~B}^{2}-1.01 \mathrm{C}^{2}+
$$



lack of fit F-value of 1.98 and the $p$-value of 0.2661 implied it was unimportant due to relative pure error. The not significant of value of lack of fit indicated the model was fitted with good prediction (Singh et al., 2017). In addition to, the value of the determination coefficient $\left(\mathrm{R}^{2}\right)$, adjusted coefficient (Adj $\mathrm{R}^{2}$ ) and coefficient of variation were $0.9497,0.8994$ and $0.56 \%$, respectively. The $\mathrm{R}^{2}$ value of the quadratic regression model showed that only 0.0503 of the total variations were not explained by the model. Adjust $\mathrm{R}^{2}$ of 0.8994 , which also confirmed that the model was highly significant. Besides, the low value of the coefficient of variation clearly indicated a better precision and reliability in conducted experiments. The ANOVA indicated that the independent variables studied hydrolysis time, liquid-solid ratio, PCA concentration were significant factors ( $p$-value $<0.05$ ) (Karacabey et al., 2010), and the quadratic terms (AC-PCA concentration and hydrolysis time) significantly affected the total purine yield. Contour plots were constructed to study interaction effects of the factors on the responses variables while keeping other factors at its medium value. Different shapes of contour plots indicated different type of interactions between the factors. The shape of elliptical showed that interactions between corresponding factors were significant, although, the reciprocal interactions between the corresponding factors are insignificant as represented by a circular contour plot (Kamble et al., 2018). The quadratic equation and ANOVA showed that AC (PCA concentration 
and hydrolysis time) have strength interaction. The interaction between PCA concentration and

hydrolysis temperature was represented by contour plot shown in Fig. 5. As excepted, the contour plot was elliptical, which indicated the interaction among them was significant. Fig. 5 showed that PCA concentration exhibited a significant effect whereas hydrolysis time. An increase in total purine yield resulted when the concentration of PCA (A) was added in the range from 70 to $82^{\circ} \mathrm{C}$. Likewise, as the time of hydrolysis (C) increased in the range from 50 to 56 , total purine extraction percent increased. Finally, the optimum conditional for PCA purine extraction method given by the software of Design-Expert 8.0.6 was acid concentration 80.97\%; temperature $79.78{ }^{\circ} \mathrm{C}$; hydrolysis time $54.20 \mathrm{~min}$; liquid-solid ratio $50.78: 1$ and the extraction percent of total purine was 86.15 . Then, according to the actual operating conditions, the optimum predicted process parameters were adjusted to acid concentration $80 \%$; temperature $80^{\circ} \mathrm{C}$; hydrolysis time $55 \mathrm{~min}$; liquid-solid ratio of 50:1 and the next verification test was carried out.

Mix-acid method

As shown in Table 3, three most important variables affecting extraction efficiency of total purine were hydrolysis time, the temperature of hydrolysis and TFA concentration, according to the screening by Plackett-Burman design. These three factors were further optimized by BBD. The equations below show the relationship of the three factors and extraction yield.

Total purine yield $(\%)=104.26+0.39 \mathrm{~A}+0.50 \mathrm{~B}+0.35 \mathrm{C}+1.33 \mathrm{AB}-0.71 \mathrm{AC}-0.77 \mathrm{BC}-2.65 \mathrm{~A}^{2}$

$$
-0.72 B^{2}-1.24 C^{2}
$$


The experimental design and analysis of variance (ANOVA) result of the model was shown

295

296

297

298

299

300

301

302

303

304

305

306

307

308

309

310

311

312

313

in Table S2 and Table 5. The value of $p$ less than 0.001 and non-significant value of lack of fit $(\mathrm{F}=0.59, p$-value $=0.6523)$ indicated the model is fitted with good prediction. The model $\mathrm{F}$-value of 40.10 indicated the model was significant and only a $0.01 \%$ chance that "Model F-value" this large could occur due to noise. Moreover, the model has a high value of $\mathrm{R}^{2}(0.9810), \mathrm{Adj}^{2}$ $(0.9565)$ and Pre $\mathrm{R}^{2}(0.8858)$, indicating a good agreement between the experimental results and predicted values of the response. Furthermore, in this paper "Adeq precision" of $17.524>4$, which implied this model can be used to navigate the design space. At the same time, the $p$ values of $\mathrm{A}, \mathrm{B}, \mathrm{C}, \mathrm{AB}, \mathrm{AC}, \mathrm{BC}, \mathrm{A}^{2}, \mathrm{~B}^{2}$ and $\mathrm{C}^{2}$ were all lower than 0.05 demonstrating that they were significant variables.

The mutual effect of TFA concentration and hydrolysis temperature was represented in Fig. 6 A. The counter plots show elliptical shaped indicating the significant interaction. Moreover, in a certain range, the extraction percent of total purine increased with TFA concentration and hydrolysis temperature. Increased TFA concentration and hydrolysis temperature led to the increase in total purine yield, but slightly decreased when exceeded the threshold levels of $89.00 \%$ and $92.00{ }^{\circ} \mathrm{C}$. The interactions between hydrolysis time and temperature was significant because of elliptical shape of contour plot (Fig. 6 B). An increase in the yield of total purine could be achieved with the controlled hydrolysis time was 8-13 min. Similar interactive effects were observed when TFA concentration and hydrolysis time were considered (Fig. 6 C). It was obvious that the extraction percent of total purine was the highest when the hydrolysis time and 
314 TFA concentration were $10.20 \mathrm{~min}$ and $87.00 \%$, respectively. Finally, BBD experiment

315 predicted that the highest extraction percent was $104.51 \%$, and the extraction conditions were as

316 follows: mixture acid $88.00 \%$ TFA/80.00\% FA (v/v, $1: 1)$; temperature $91.83^{\circ} \mathrm{C}$; hydrolysis time

$3179.43 \mathrm{~min}$; liquid-to-solid ratio 30:1. With some modifications, TFA concentration of $90.00 \%$,

318 temperature of $90.00^{\circ} \mathrm{C}$, hydrolysis time $10.00 \mathrm{~min}$ were used to verification test.

319 Determination of the optimal method

In order to determine the best extraction method, the extraction yields of the two methods were compared; the results were given in Table 6 . The actual extraction yield of total purine were $83.75 \pm 2.65 \%$ (PCA method) and $103.94 \pm 3.85 \%$ (mix-acid method), respectively. The relative error with the predicted value were less than $5 \%$. The experimental results were well agreement with the predicted results. The result indicated that the model developed was considered to be accurate and reliable. In addition, the extractions of the total purine by the mixed-acid method was higher than those by the PCA method. These differences were likely due to protective effects of FA on purine bases. Moreover, TFA could promote complete dissolution of purine bases. In addition, the mixed-acid treatment was timesaving and could effectively avoid the production of toxic chlorine. Therefore, the mixed-acid method was chosen for the extraction of purine bases from different marine fish.

Method Validation 
334 The LODs ranged from 0.0118 to $0.0774 \mathrm{mg} / \mathrm{L}$, which were considered excellent. Furthermore,

335 the $\mathrm{R}^{2}$ values were all above 0.9999 , indicating a good linearity.

336 Standards were used to evaluate the precision of the method. For the repeatability and

337 recovery tests, Scophthalmus maximus (dorsal muscles) samples were prepared by the method

338 described previously. As shown in Table 8, the the deviation in results were less than $0.69 \%$,

339 which indicated that the HPLC method was highly reproducible. The mean repeatability of the

340 method for quantification of adenine, guanine, hypoxanthine, and xanthine were $1.32 \%, 0.87 \%$,

$3410.83 \%$, and $1.77 \%$, respectively. By this method, average recoveries ranged from $94.90 \%$ to

342 104.51\%. These results suggest that the mixed-acid method avoided damaging the purine bases,

343 and confirm the validity of the method.

344 Purine contents in edible parts of marine fish

345 The contents of the four purines in different edible parts of marine fish were determined by

346 the method described above; results are shown in Table 9. Among the marine fish evaluated, the

347 total purine content (dorsal muscles + abdominal muscles + skin + entrails + eyes) was highest in

348 Sphyraena. In contrast, Rajiformes exhibited the lowest total purine content. Considering only

349 the edible parts of the fish (muscles, skin, and eyes) Scophthalmus maximus, Sphyraena, and

350 Sardinella had the highest purine contents. Rajiformes and Anguillidae had the lowest purine

351 contents and would thus be more suitable for a low-purine diet. To control the concentration of

352 serum uric acid and avoid hyperuricemia and gout, it is best to reduce the consumption of high-

353 purine fish such as Scophthalmus maximus and Sphyraena. 
354

355

356

357

358

359

360

361

362

363

The purine contents in fish viscera were significantly higher than those in muscles. The total purine content in viscera ranged from $1085.61 \mathrm{mg} / \mathrm{kg}$ to $2719.72 \mathrm{mg} / \mathrm{kg}$, but the muscle samples contained only 551.33-1188.12 mg/kg (dorsal muscles) and 376.94-1302.82 mg/kg (abdominal muscles) total purines, with Sphyraena and Scophthalmus maximus exhibiting higher total purine contents than the muscles samples of other fish. This may be due to the higher visceral metabolic rate in the intestine of these species, which could promote the formation of purine bases.

Furthermore, all muscle samples (dorsal muscles and abdominal muscles) were found to contain higher amounts of hypoxanthine than the other three purine bases. This observation is consistent with the report by Qu et al. (2016), who found that hypoxanthine content was the dominant purine in the muscles of Lateolabrax japonicus, followed by adenine, guanine, and xanthine.

accounting for 74.22 to $95.48 \%$ of the total purine content. The total purine content of skin varied significantly between the different species of marine fish. Anguillidae skin exhibited total purine content of $486.56 \mathrm{mg} / \mathrm{kg}$, whereas the purine content of Sphyraena skin was ten times higher. This might be related to the different habitats and growth patterns of the marine fish. Theoretically, the four purine bases can be transformed to uric acid in an equal manner, but hypoxanthine and adenine exhibit the greatest hyperuricemic effect (Clifford et al., 1976). The main difference between the purine contents in viscera compared with that of the eyes was the dominant purine. As seen in Table 9, viscera were rich in adenine, guanine, and hypoxanthine, whereas eyes contained the highest level of guanine. Furthermore, it is worth noting the purine 
374

375

content in fish eyes, which ranged from $1010.64 \mathrm{mg} / \mathrm{kg}$ to $3990.19 \mathrm{mg} / \mathrm{kg}$. In some regions, especially in China, consumers commonly eat fish eyes. Considering the high purine content of fish eyes and the pain and potential joint damage caused by hyperuricemia and gout, the consumption of fish eyes should be avoided, even though they are rich in nutrients such as collagen and unsaturated fatty acids.

\section{Effect of boiling on purine content}

Changes in the purine content of muscle during boiling

$$
\text { Previous studies have demonstrated that processes such as boiling, steaming, and }
$$
microwaving can significantly reduce the purine content in foods. Among these processes, boiling is one of the most effective approaches to decreasing purine content. However, most studies on the effect of boiling on purine levels have mainly focused on meats such as chicken and beef, while less attention had been paid to the effect in aquatic organisms (Brulé, Sarwar \& Savoie 1989; Young, 1983). The changes in purine content during the boiling of marine fish measured during this study are shown in Fig. 7.

Hypoxanthine was the major purine base measured in the muscle samples (Fig. 7). In the dorsal and abdominal muscles of Scophthalmus maximus, the amounts of adenine, guanine, and hypoxanthine decreased after boiling in water, but no changes were observed in the amount of xanthine present (Fig. 7). Among the purines measured, hypoxanthine was found to undergo the greatest reduction, from $867.90 \mathrm{mg} / \mathrm{kg}$ to $258.24 \mathrm{mg} / \mathrm{kg}(70.24 \%)$ in dorsal muscles and from $933.94 \mathrm{mg} / \mathrm{kg}$ to $442.98 \mathrm{mg} / \mathrm{kg}(52.57 \%)$ in abdominal muscles. Several studies have determined 
394

395

396

397

398

399

400

401

402

403

404

405

406

407

408

409

410

411

412

413

that hypoxanthine and free hypoxanthine-related compounds have good solubility and can be released easily from foods during cooking (Brulé, Sarwar \& Savoie 1989; Young, 2015). Our findings are also comparable to those of Lou, Lin, and Benkmann (2001), who found that free purine bases in grass shrimp could be easily released and transferred to the cooking liquid during the cooking process. Furthermore, the contents of adenine and guanine decreased slightly after boiling; the amounts of adenine and guanine released into the cooking water were $35.89 \%$ and $15.92 \%$, respectively, in dorsal muscles, and $32.21 \%$ and $29.18 \%$, respectively, in abdominal muscles. The xanthine contents in muscles were relatively low to begin with, and exhibited nearly no change after boiling.

As for the effect of boiling time on changes in purine content, the contents of the four purine bases decreased more extensively with prolonged treatment time, and most purines in the dorsal muscles were reduced within 12-15 min. In comparison, the total purine and hypoxanthine contents in abdomen muscles decreased significantly within 0-3 minutes, declining by $64.63 \%$ and $49.13 \%$, respectively (Fig. 7).

Changes in purine content of skin during boiling

Changes in the purine content of the skins were similar to those of muscles. Boiling reduced the amounts of purine base presents. As shown in Fig. 8, boiling led to a slight decrease in total purine content, from 1596.68 to $1117.41 \mathrm{mg} / \mathrm{kg}$ in Scophthalmus maximus skin. Hypoxanthine decreased rapidly (by $41.47 \%$ ) in the first $3 \mathrm{~min}$, after which time the rate of removal slowed down. Guanine was the major purine base in the skin samples; however, adenine and guanine 
414 decreased only slightly after boiling, declining by 35.71 and $23.20 \%$, respectively. Boiling had

415 the greatest effect on the removal of hypoxanthine among the four purines, with the content

416 decreasing from $324.04 \mathrm{mg} / \mathrm{kg}$ to $82.51 \mathrm{mg} / \mathrm{kg}$.

417 Change in purine content of the cooking liquid during boiling

418 In order to explore the transfer of purine between the fish parts and the cooking water 419 during boiling, the changes in purine content of the cooking water were also determined. As 420 shown in Fig. 9, with increased boiling time, the contents of the four purines in the cooking 421 liquid increased gradually over $15 \mathrm{~min}$. The total purine content of the water increased 422 remarkably within the first $3 \mathrm{~min}$. The cooking liquid contained abundant levels of hypoxanthine, 423 which was measured at concentrations approximately three times higher than those of the other 424 three purines combined. The hypoxanthine content significantly increased within the first 9 min 425 and remained stable thereafter. There was no significant change in xanthine content over 15 min 426 of boiling. The adenine and guanine contents in the cooking liquid increased sharply from 3 to $42715 \mathrm{~min}$, by $161.99 \mathrm{mg} / \mathrm{kg}$ and $180.10 \mathrm{mg} / \mathrm{kg}$, to final contents of $200.26 \mathrm{mg} / \mathrm{kg}$ and $230.94 \mathrm{mg} / \mathrm{kg}$, 428 respectively. These results confirm that the purines contained in the edible parts of the marine 429 fish were transferred to the cooking liquid. This result agrees with the findings of Young (2015), 430 who reported that the level of hypoxanthine in tissues decreased during cooking as it was 431 removed by the cooking liquids.

\section{Conclusions}



maximus, Sphyraenus, and Sardine containing higher purine levels than the other fish tested.

435 Moreover, the dominant purine and content of each purine varied significantly between the different parts of the marine fish, where purine content in the viscera and eyes of the fish were higher than that in muscles. The muscle samples (dorsal and abdominal muscles) were found to contain higher amounts of hypoxanthine, whereas the major purine base in the eyes was guanine, the skin of the marine fish contained large amounts of guanine and hypoxanthine, and the viscera were rich in adenine, guanine, and hypoxanthine. We confirmed that boiling significantly reduced the purine contents in the fish, as the purines were transferred to the cooking liquid. of hyperuricemia and gout.

\section{Acknowledgment}

We thank all people who contributed directly or indirectly to this work. We thank all people who contributed directly or indirectly to this work, We are grateful to National \& Local Joint Engineering Research Center of Storage, Processing and Safety Control Technology for Fresh Agricultural and Aquatic Products-Bohai University for infrastructure this study.

\section{References}

Brulé D, Sarwar G, Savoie L. 1989. Effect of methods of cooking on free and total purine bases in meat and fish. Canadian Institute of Food Science \& Technology Journal 22:248251 DOI 10.1016/S0315-5463(89)70391-6 
453

454

455

456

457

458

459

Clariana M, Gratacóscubarsí M, Hortós M, García JA, Castellari M. 2010. Analysis of seven purines and pyrimidines in pork meat products by ultra high performance liquid chromatography-tandem mass spectrometry. Journal of Chromatography A 1217: 42944299 DOI 10.1016/j.chroma.2010.04.033

Clifford AJ, Riumallo JA, Young VR, Scrimshaw NS. 1976. Effect of oral purines on serum and urinary uric acid of normal, hyperuricemic and gouty humans. Journal of Nutrition 106: 428-450 DOI 10.1093/jn/106.3.428

Farrokhnia M , Safekordi A, Rashidzadeh M, Khanbabaei G, Anari RA, Rahimpour M. 2016. Development of porous nanocomposite membranes for gas separation by identifying the effective fabrication parameters with Plackett-Burman experimental design. Journal of Porous Materials 23(5):1279-1295 DOI 10.1007/s10934-016-0187-y

Fukuuchi T, Yasuda M, Inazawa K, Ota T, Yamaoka N, Mawatari K, Mawatari K, Kaneka K. 2013. A simple HPLC method for determining the purine content of beer and beer-like alcoholic beverages. Analytical Sciences 29: 511-517 DOI 10.2116/analsci.29.511

Grosso C, Ferreres F, Gil-Izquierdo A, Valentão P, Sampaio M, Lima J, Andrade PB. 2014. Box-Behnken factorial design to obtain a phenolic-rich extract from the aerial parts of Chelidonium majus L. Talanta 130:128-136 DOI 10.1016/j.talanta.2014.06.043

Goldberg EL, Asher JL, Molony RD, Shaw AC, Zeiss CJ, Wang C, Morozova-Roche LA, Herzog RI, Iwasaki A, Dixit VD. 2017. $\beta$-Hydroxybutyrate deactivates neutrophil NLRP3 
472

473

inflammasome to relieve gout flares. Cell Reports 18: 2077-2087 DOI

10.1016/j.celrep.2017.02.004

Gowda S, Desai PB, Kulkarni SS, Hull VV, Math AAK, Vernekar SN. 2010. Markers of renal function tests. North American Journal of Medical Sciences 2: 170-173.

Jamil NH, Halim NRA, Sarbon NM. 2016. Optimization of enzymatic hydrolysis condition and functional properties of eel (Monopterus sp.) protein using response surface methodology (RSM). International Food Research Journal 23(1): 1-9.

Jaroslav H, Vladimir P, Javier F, Vojtech R. 2010. Dietary purines in vegetarian meat analogues. Journal of the Science of Food \& Agriculture 90: 2352-2357 DOI $10.1002 /$ jsfa.4089

Karacabey E, Mazza G. 2010. Optimization of antioxidant activity of grape cane extracts using response surface methodology. Food Chemistry 119: 343-348 DOI 10.1016/j.foodchem.2009.06.029

Kamble PP, Kore MV, Patil SA, Jadhav JP, Attar YC. 2018. Statistical optimization of process parameters for inulinase production from Tithonia weed by Arthrobacter mysorens strain no.1. Journal of Microbiological Methods 149: 55 DOI 10.1016/j.mimet.2018.04.019

Klampfl CW, Himmelsbach M, Buchberger W, Klein H. 2002. Determination of purines and pyrimidines in beer samples by capillary zone electrophoresis. Analytica Chimica Acta 454: 185-191 DOI 10.1016/S0003-2670(01)01570-7 
491

492

493

494

495

Li H. 2015. Determination of purines in beer by HPLC using a simple and rapid sample pretreatment. Journal of the American Society of Brewing Chemists 73: 137-142 DOI 10.1094/ASBCJ-2015-0409-01

Lou SN, Lin CD, Benkmann R. 2001. Changes in purine content of Tilapia mossambica during storage, heating and drying. Food Science and Agricultural chemistry 3: 23-29

Peng L, Song X, Shi X, Li J, Ye C. 2008. An improved HPLC method for simultaneous determination of phenolic compounds, purine alkaloids and theanine in Camellia species. Journal of Food Composition \& Analysis 21: 559-563 DOI 10.1016/j.jfca.2008.05.002

Piñeiro-Sotelo M, López-Hernández J, Simal-Lozano, J. 2002. Determination of purine bases in sea urchin (Paracentortus lividus) gonads by high-performance liquid chromatography. Food Chemistry 79: 113-117

Qu X, Sui J, Mi N, Lin H. 2016. Determination of four different purines and their changing rules in seafood by high performance liquid chromatography. Journal of the Science of Food \& Agriculture 97: 520-525 DOI 10.1002/jsfa.7755

Rong S, Zou L, Zhang Y, Zhang G, Li X, Li M, Yang F, Li C, He Y, Guan H, Guo Y, Wang D, Gui X, Ye H, Liu F, Pan H, Yang Y. 2015. Determination of purine contents in different parts of pork and beef by high performance liquid chromatography. Food Chemistry 170 DOI 303-307. 10.1016/j.foodchem.2014.08.059

Shmerling RH. 2012. Management of gout: A 57-year-old man with a history of podagra, 
510

511

512

hyperuricemia, and mild renal insufficiency. The Journal of the American Medical Association 308: 2133-2241 DOI 10.1001/jama.2012.65028

Singh A, Bajar S , Bishnoi NR. 2017. Physico-chemical pretreatment and enzymatic hydrolysis of cotton stalk for ethanol production by Saccharomyces cerevisiae. Bioresource Technology 24:71 DOI: 10.1016/j.biortech.2017.07.123

Suresh E, Das P. 2012. Recent advances in management of gout. QJM-An international journal of medicine 105: 407-417 DOI 10.1093/qjmed/hcr242

Vasiee A, Behbahani BA, Yazdi FT, Moradi S. 2016. Optimization of the production conditions of the lipase produced by Bacillus cereus from rice flour through PlackettBurman Design (PBD) and response surface methodology (RSM). Microbial Pathogenesis 101:36-43.

Yin G, Dang Y. 2008. Optimization of extraction technology of the Lycium barbarum polysaccharides by Box-Behnken statistical design. Carbohydrate Polymers 74(3):603-610

Young LL. 1983. Effect of stewing on purine content of broiler tissues. Journal of Food Science 48: $315-316$

Young LL. 2015. Purine content of raw and roasted chicken broiler meat. Journal of Food Science 47: 1374-1375 DOI 10.1111/j.1365-2621.1982.tb07689.x

Zhao J, Liang Q, Luo G, Wang Y, Zou Y, Jiang M, Yu G, Zhang T. 2005. Purine metabolites in gout and asymptomatic hyperuricemia: analysis by HPLC-electrospray tandem mass 
Figure 1

HPLC chromatogram of standards' solution

A: Adenine B: Guanine C: Hypoxanthine D: Xanthine

$\mathrm{mV}$

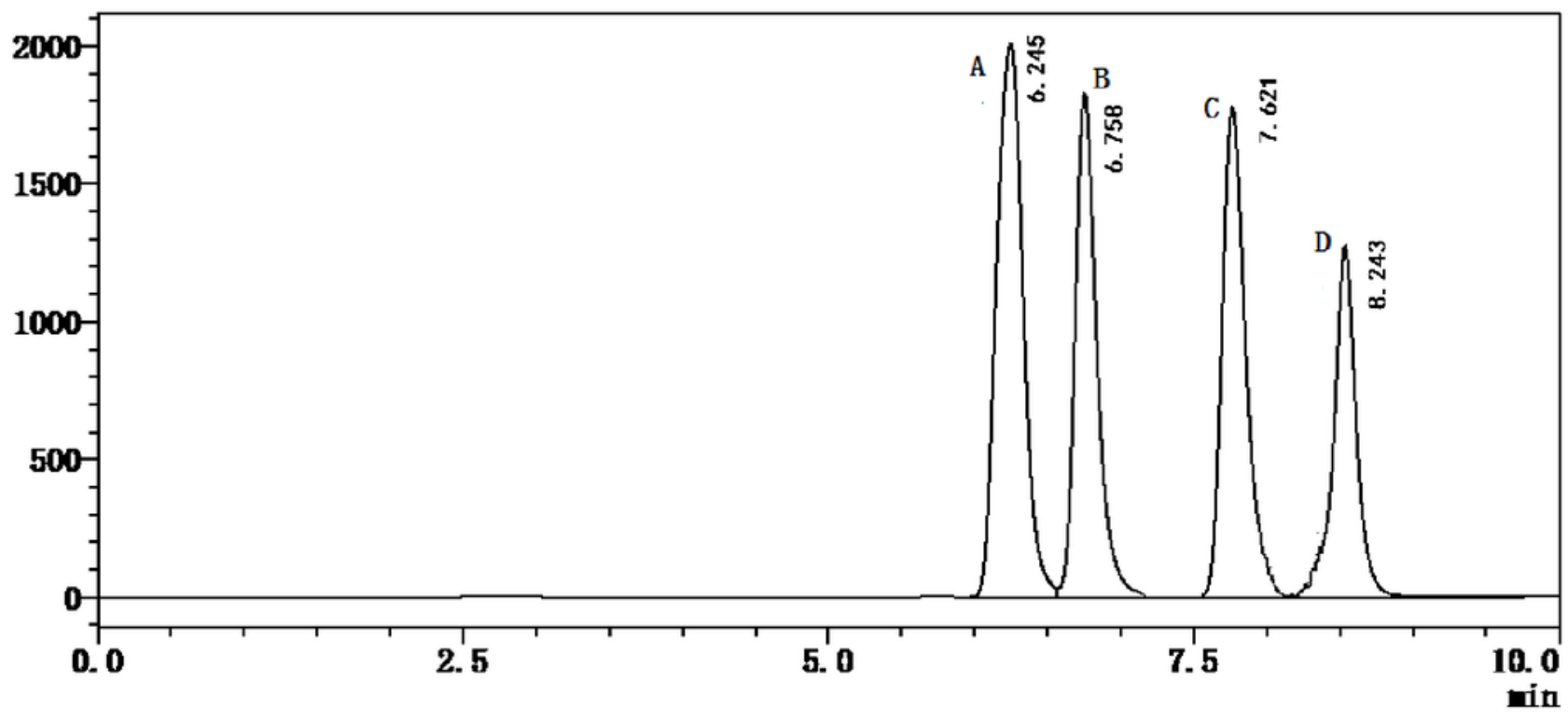


Figure 2

Influence of different factors on the extraction percent using the PCA method

(A) PCA concentration (B) Hydrolysis temperature (C) Hydrolysis time (D) Liquid-solid ratio

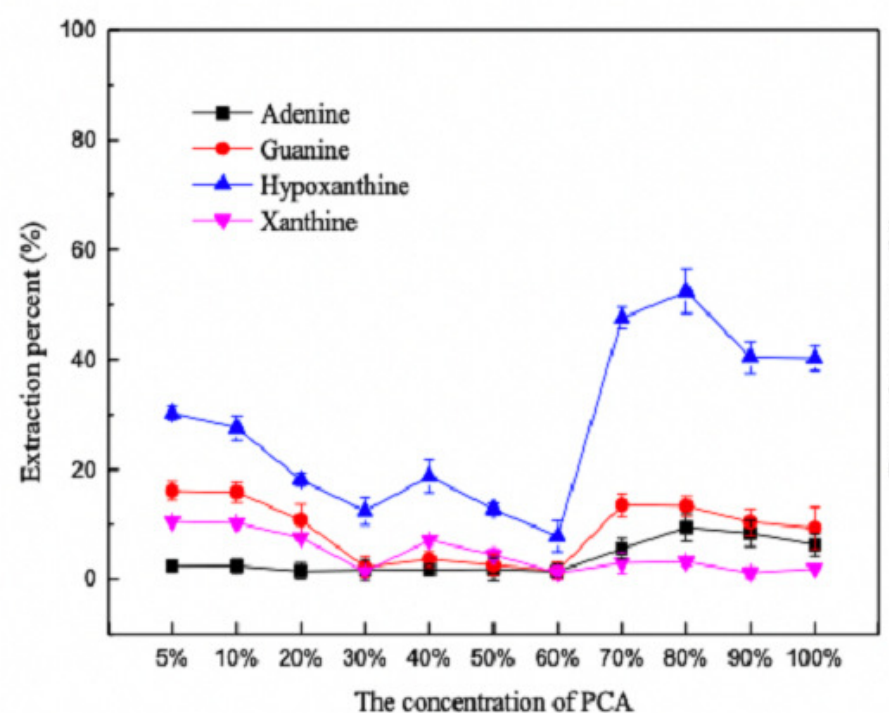

A

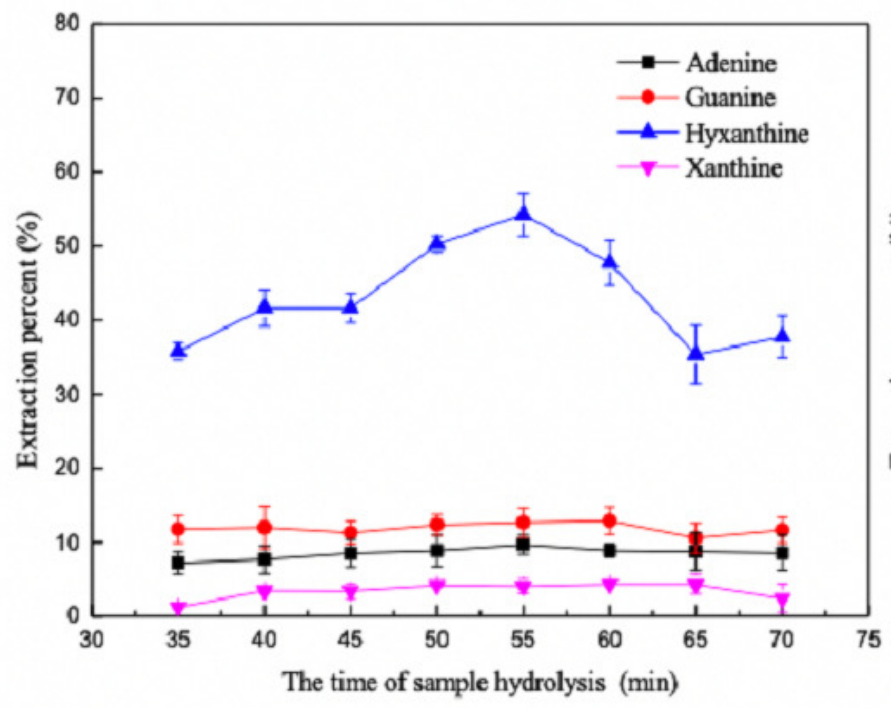

$\mathrm{C}$

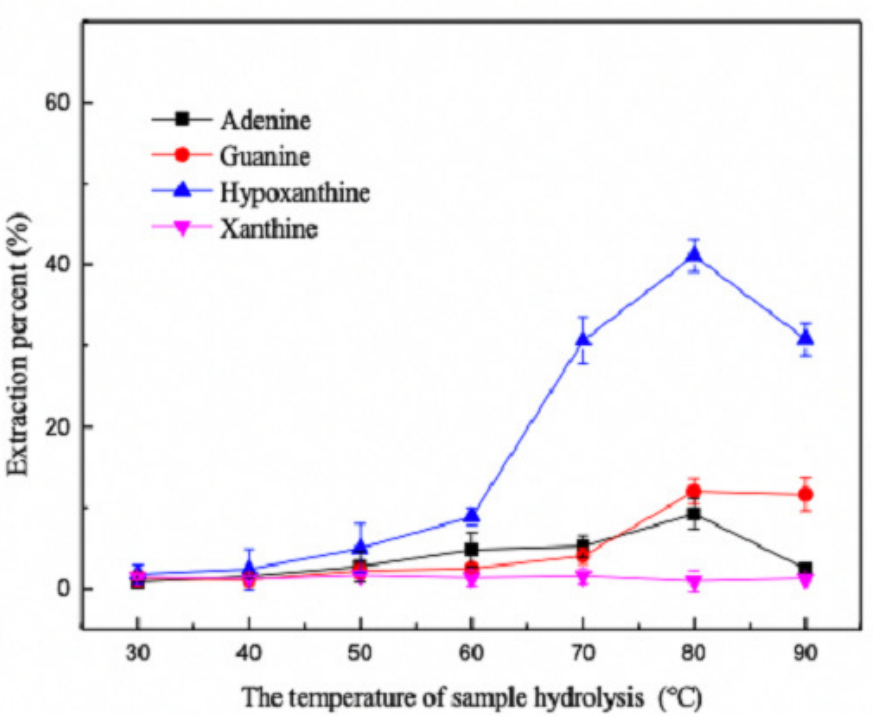

B

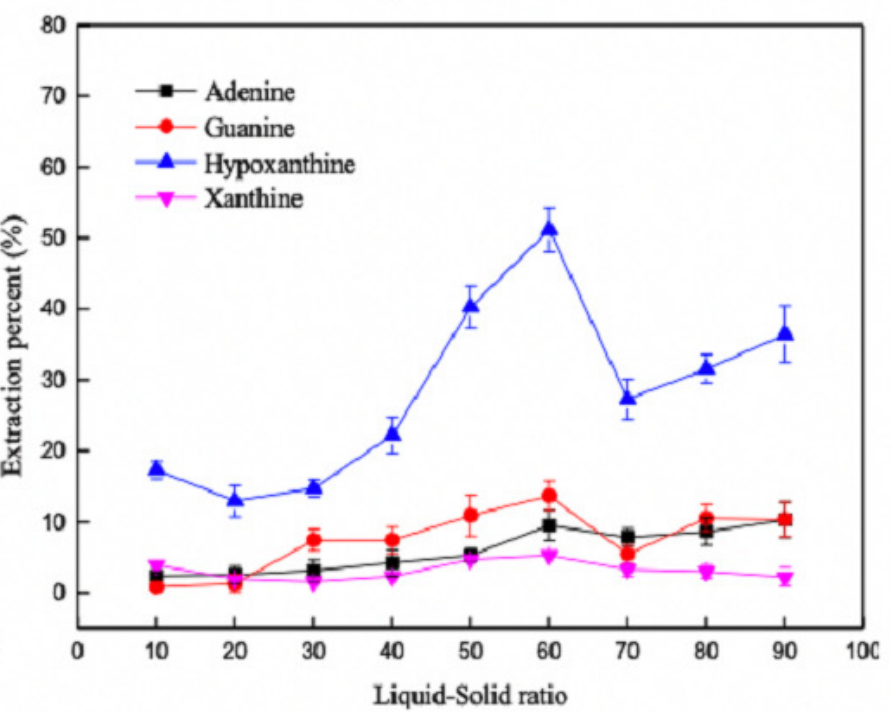

D 
Figure 3

Influence of different factors on the extraction percent using the mix-acid method
(A) Hydrolysis temperature (B) Liquid-solid ratio (C) FA concentration (D) TFA concentration
(E) Hydrolysis time 


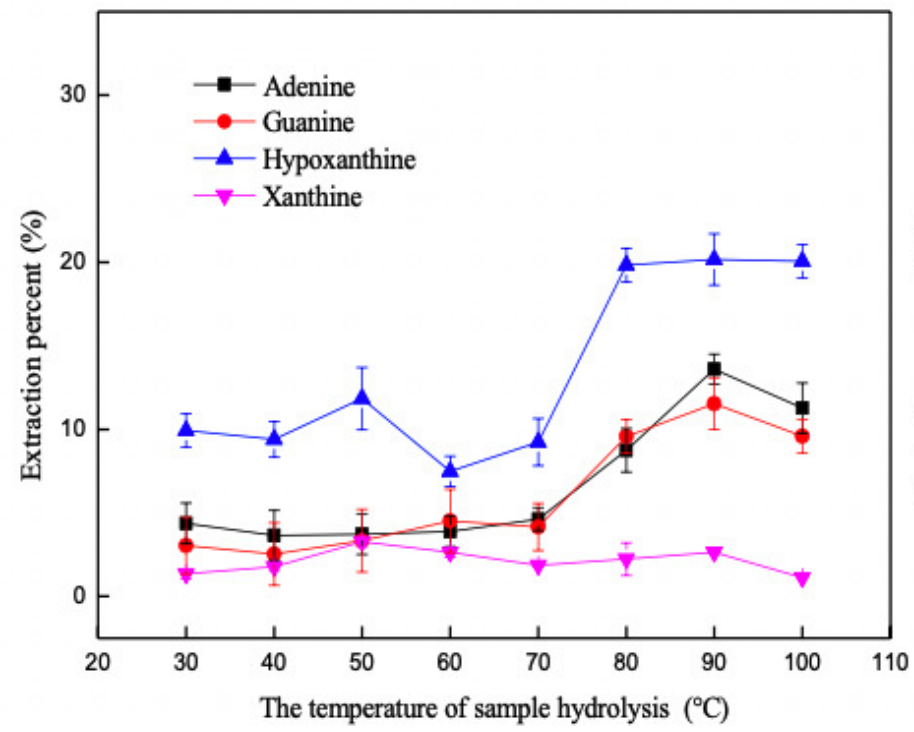

A

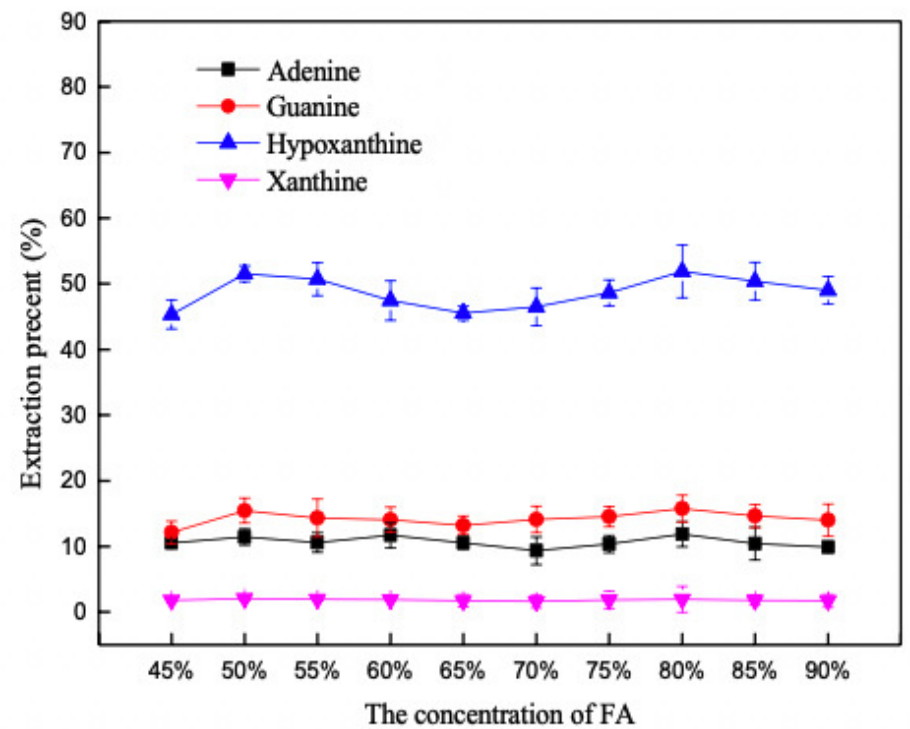

C

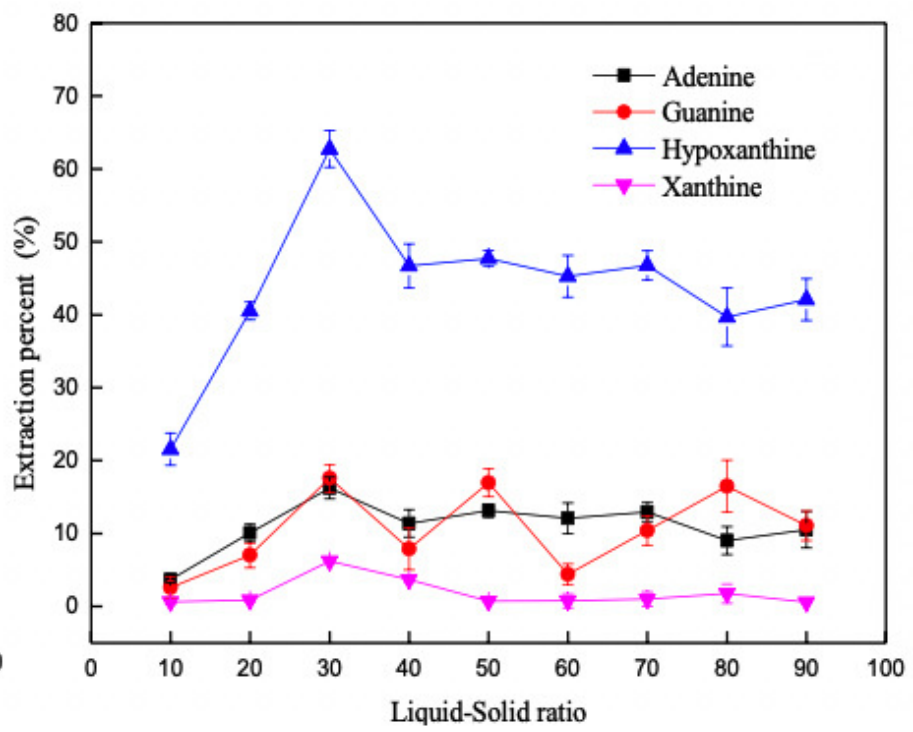

B

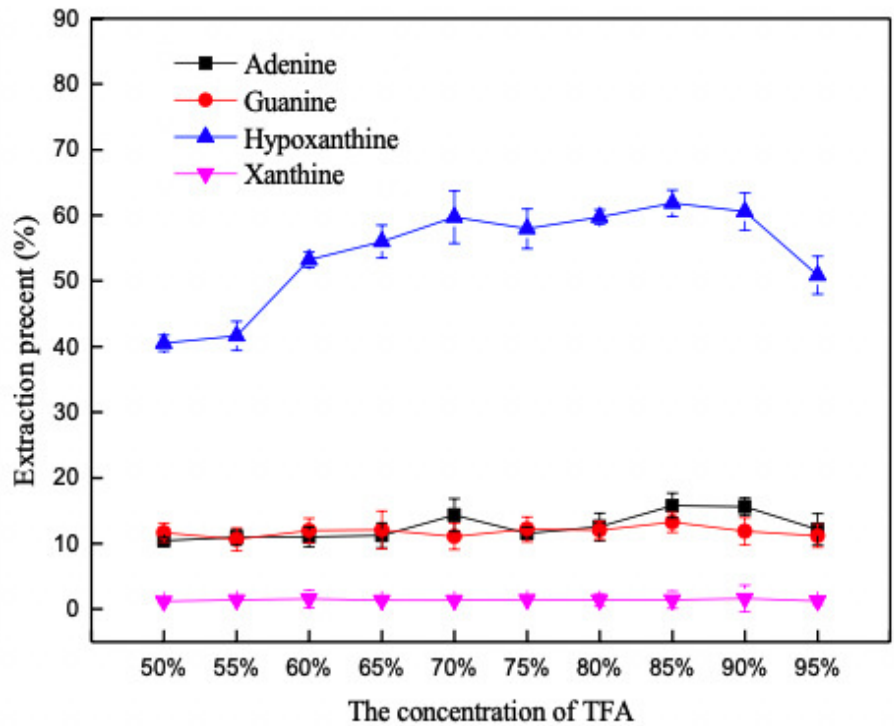

D

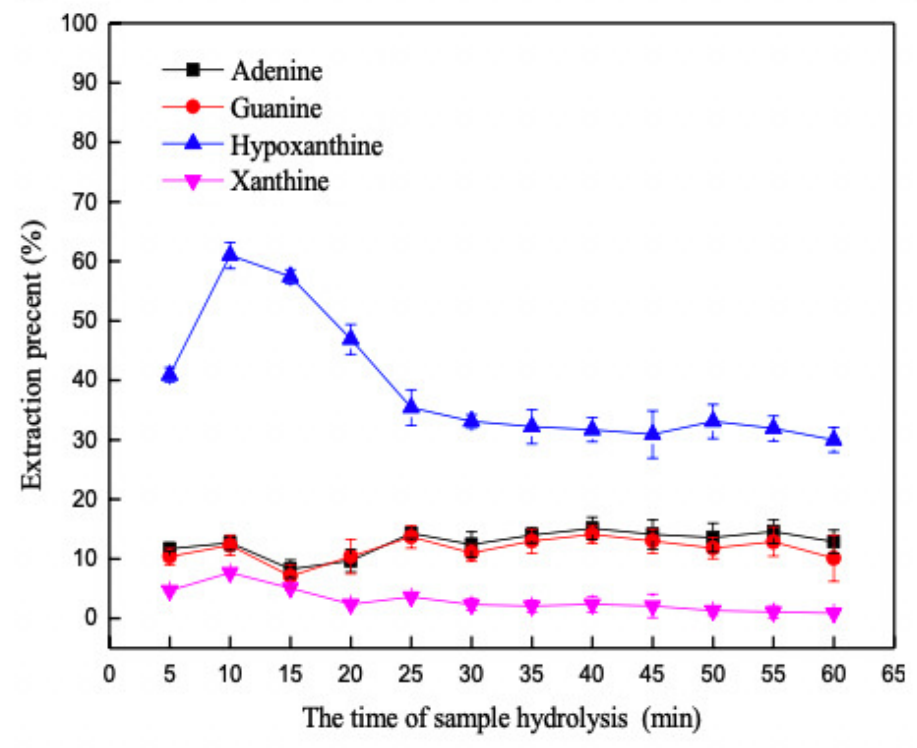

E 
Figure 4

Pareto Chart of Plackett-Burman design

\section{Pareto Chart}

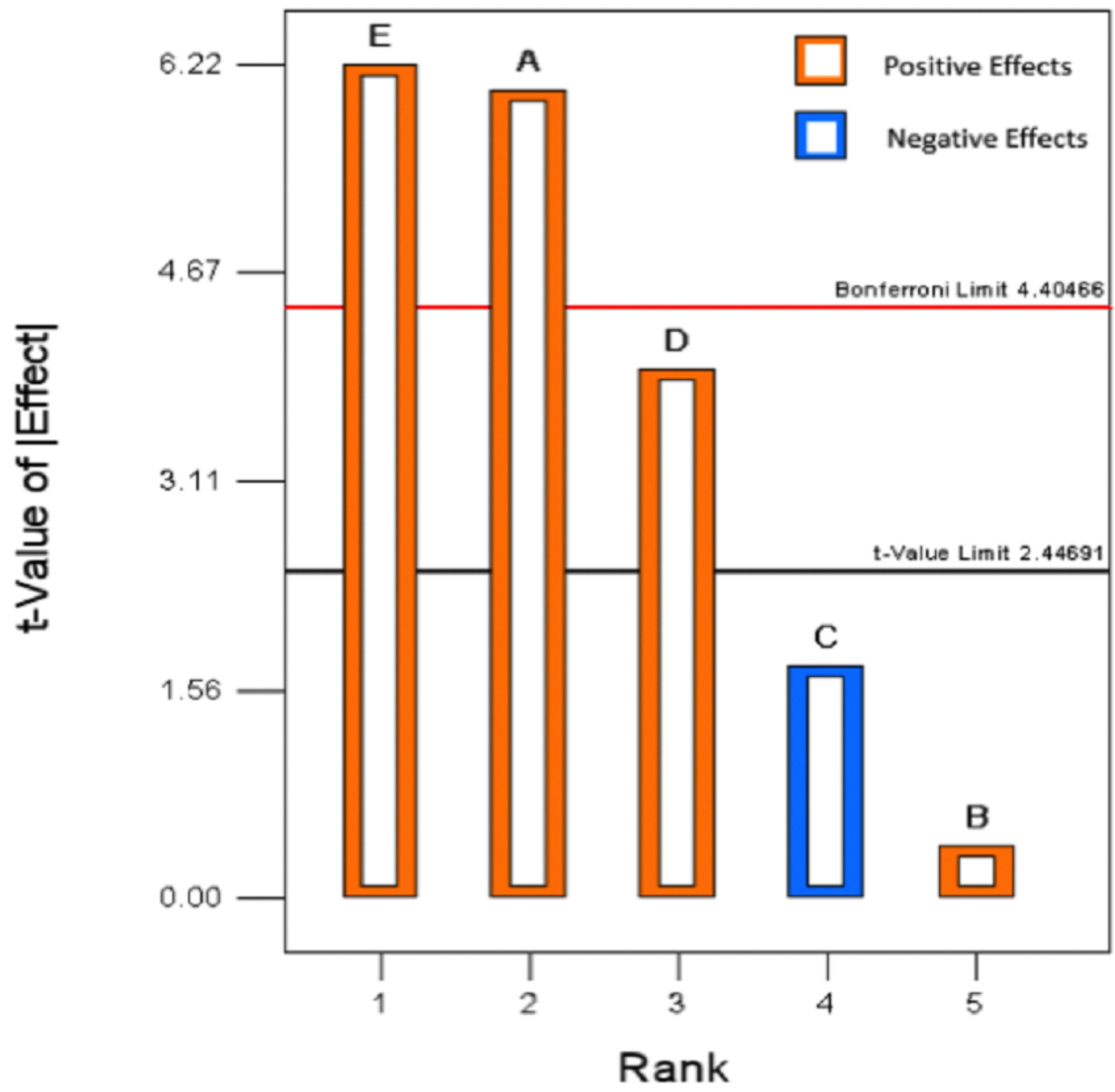


Figure 5

Contour plots of PCA method

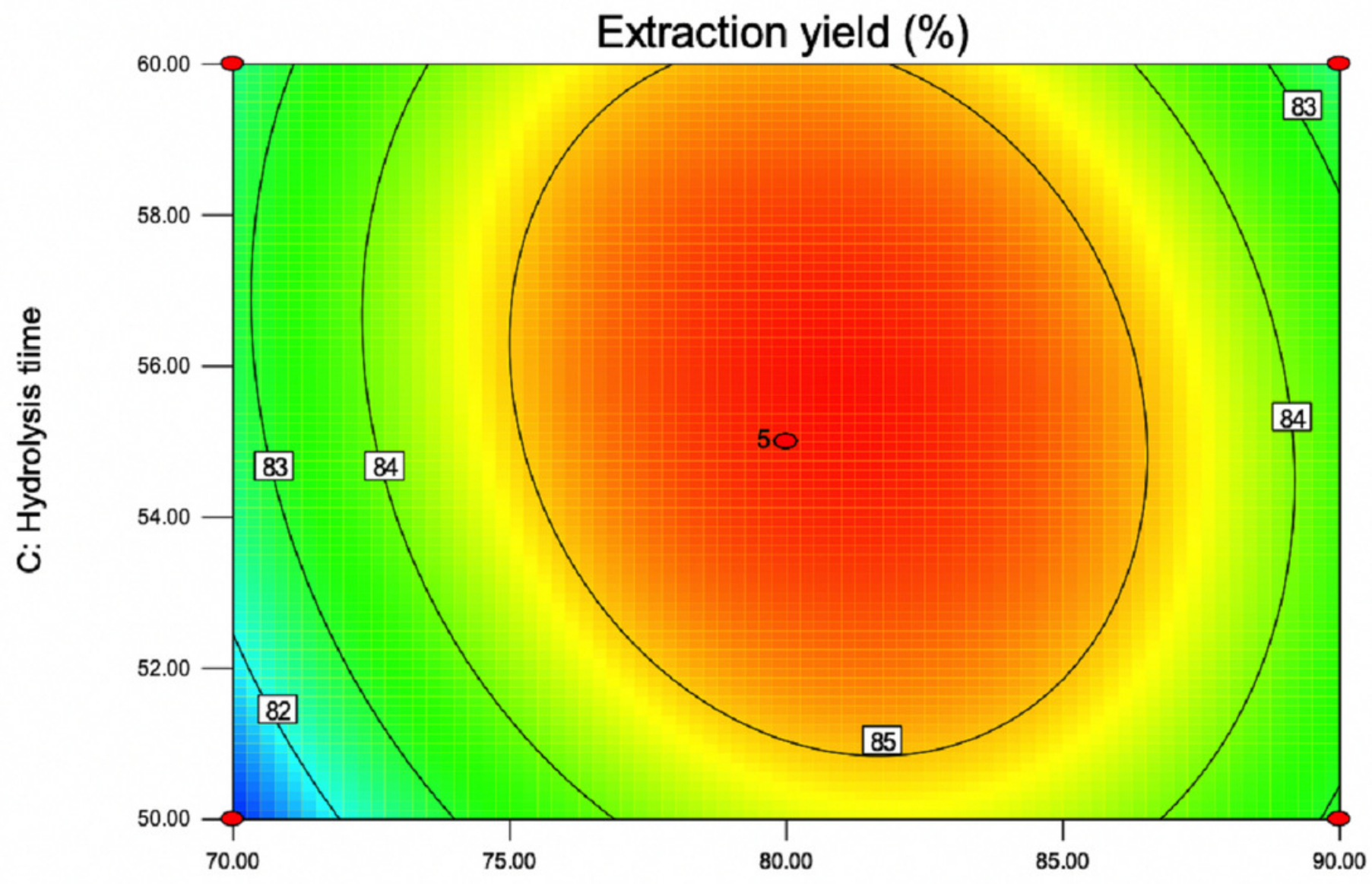

A: PCA concentration 


\section{Figure 6}

Contour plots of mix-acid method

(A) Contour plot of TFA concentration and hydrolysis temperature on extraction yield. (B) Contour plot showing the effect of hydrolysis time and temperature on extraction yield of total purine. (C) Contour plot of TFA concentration and hydrolysis time on extraction yield of total purine.

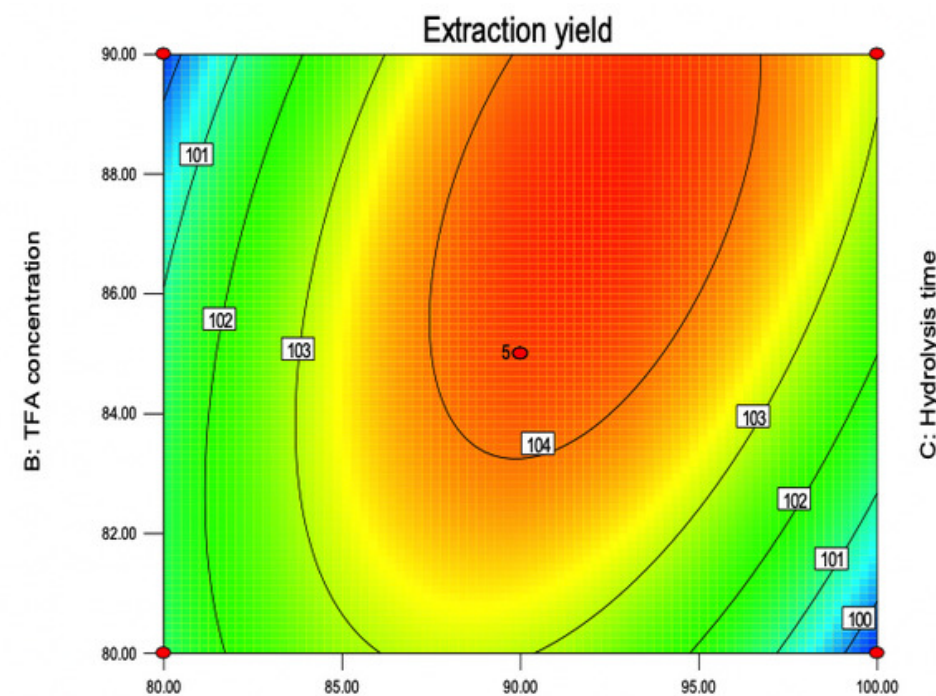

A: Hydrolysis temperature

A

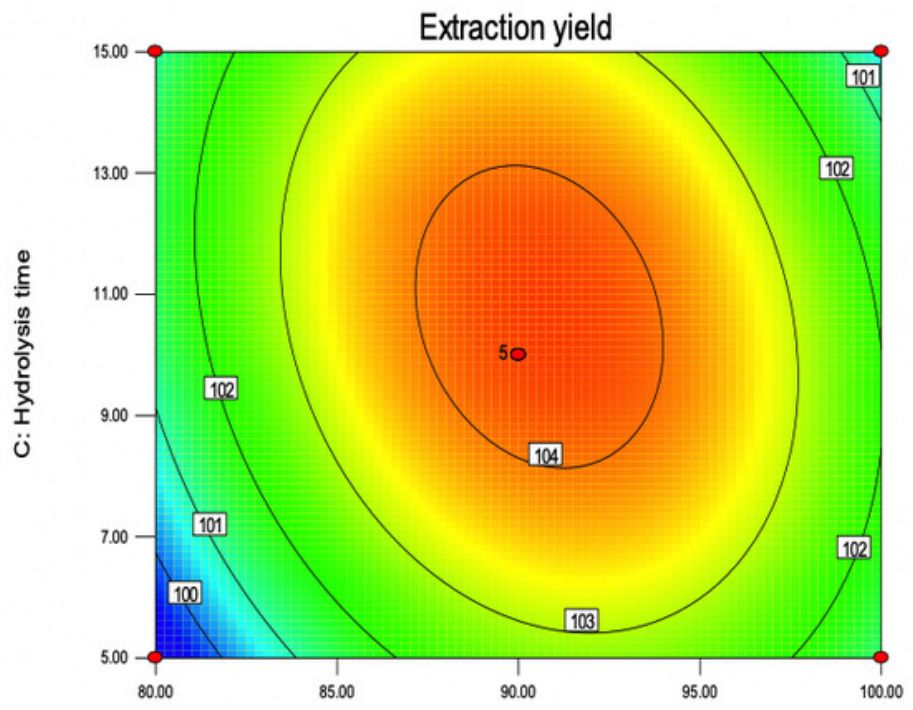

A: Hydrolysis temperature

B

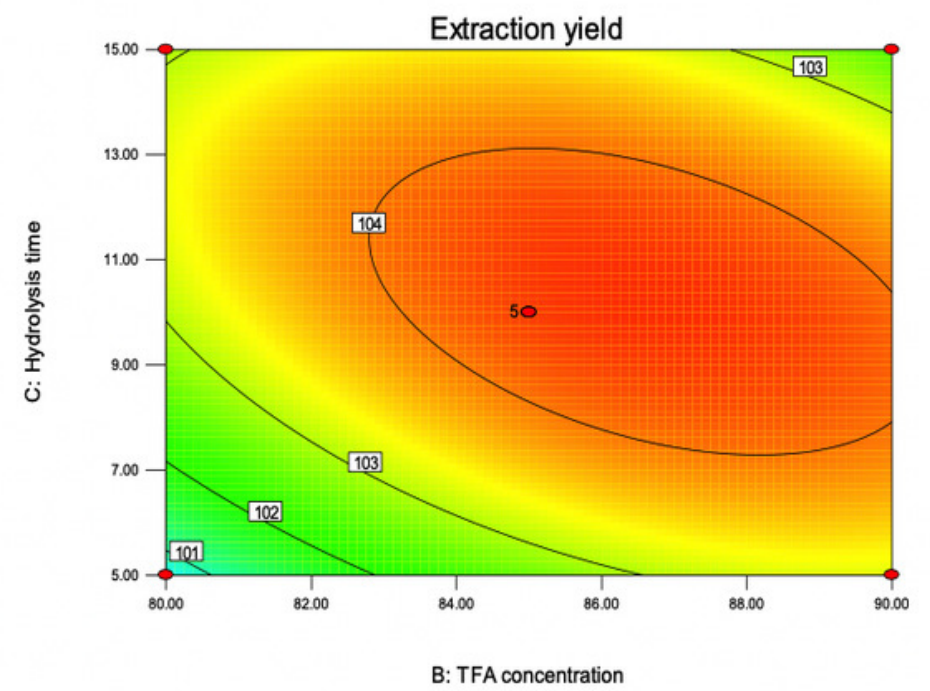

$\mathrm{C}$ 
Figure 7

Effects of boiling on the purine contents in muscles

A: dorsal muscles B: abdominal muscles 


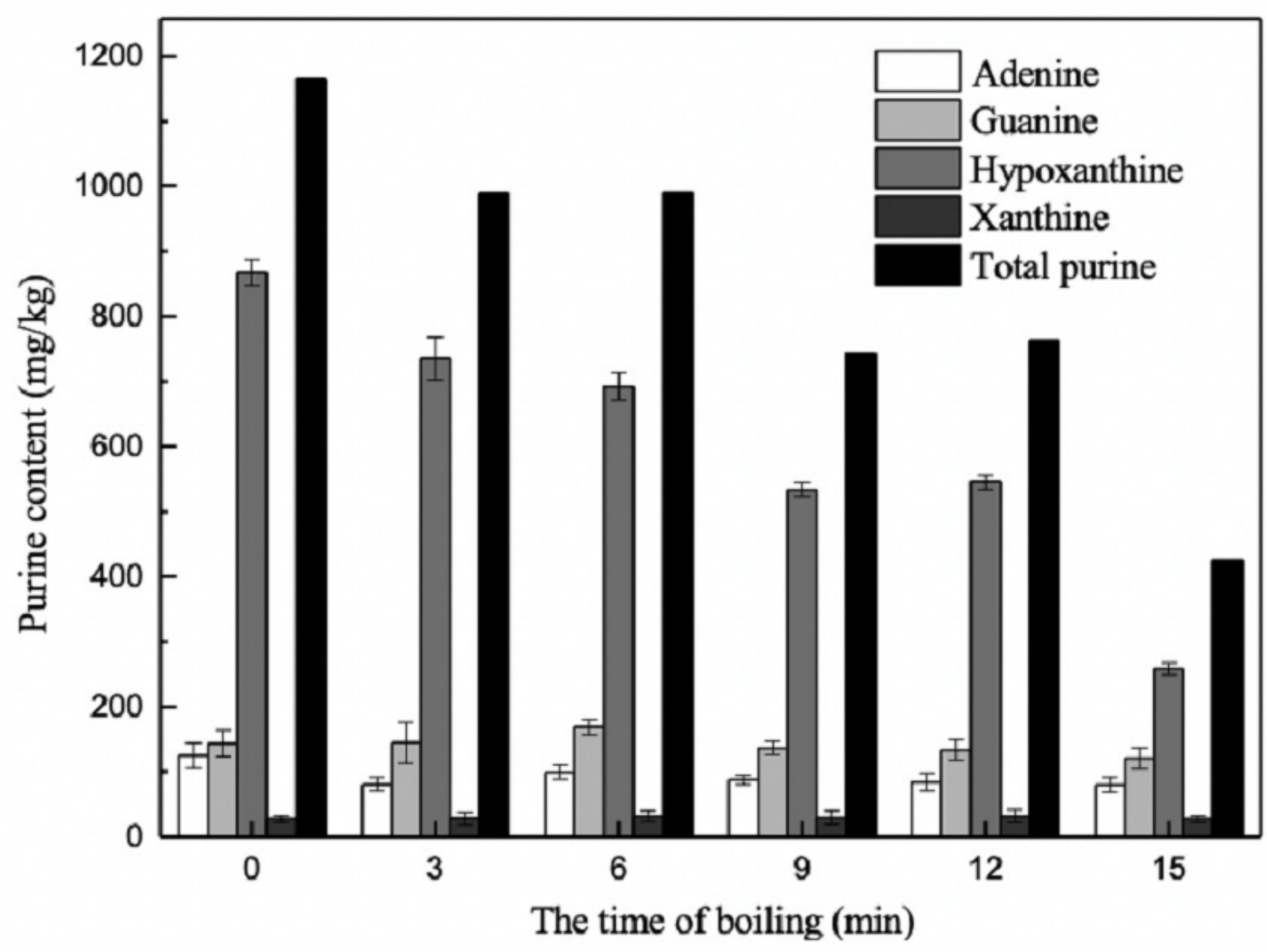

A

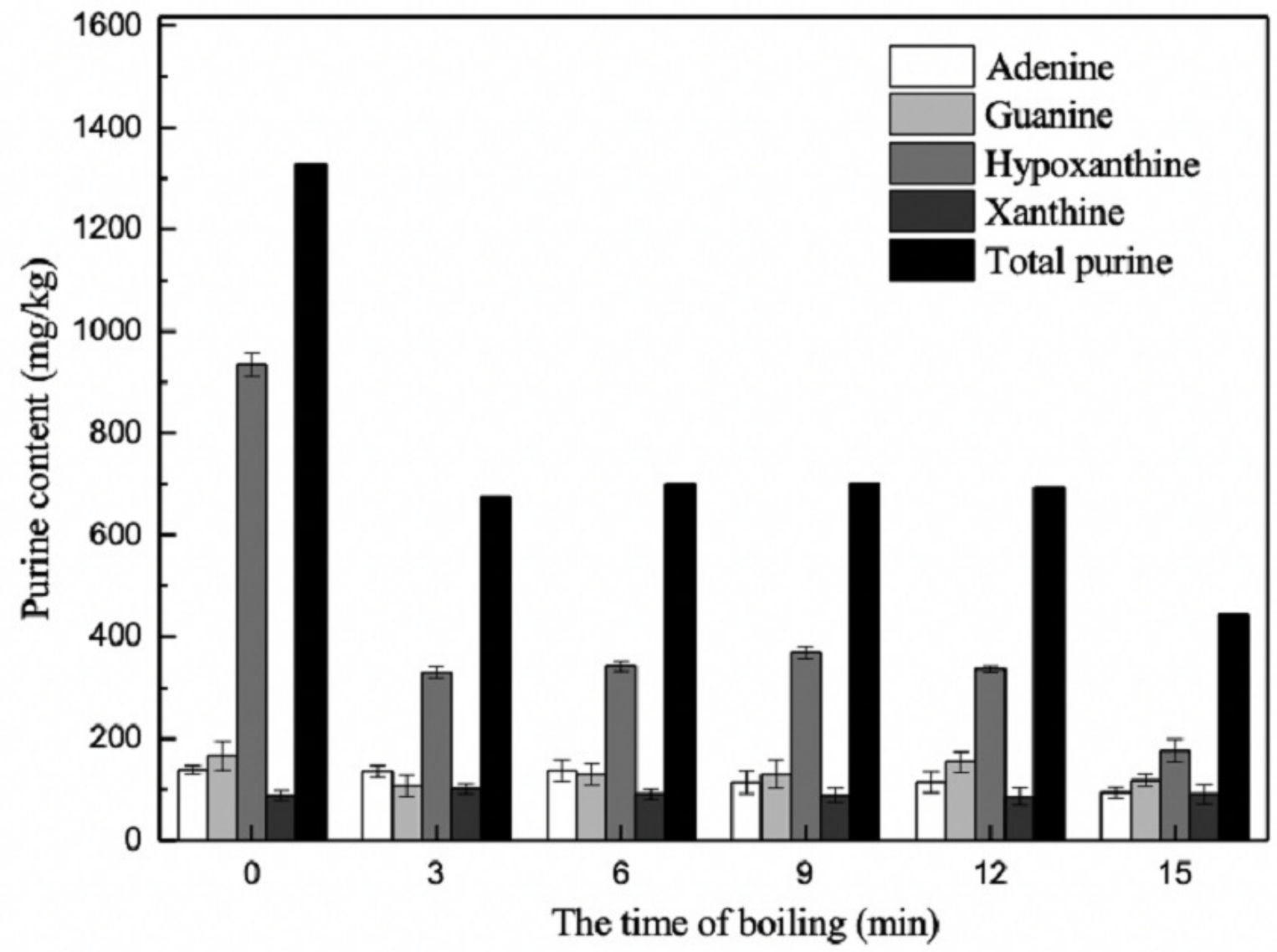


Figure 8

Effect of boiling on the purine contents in skin

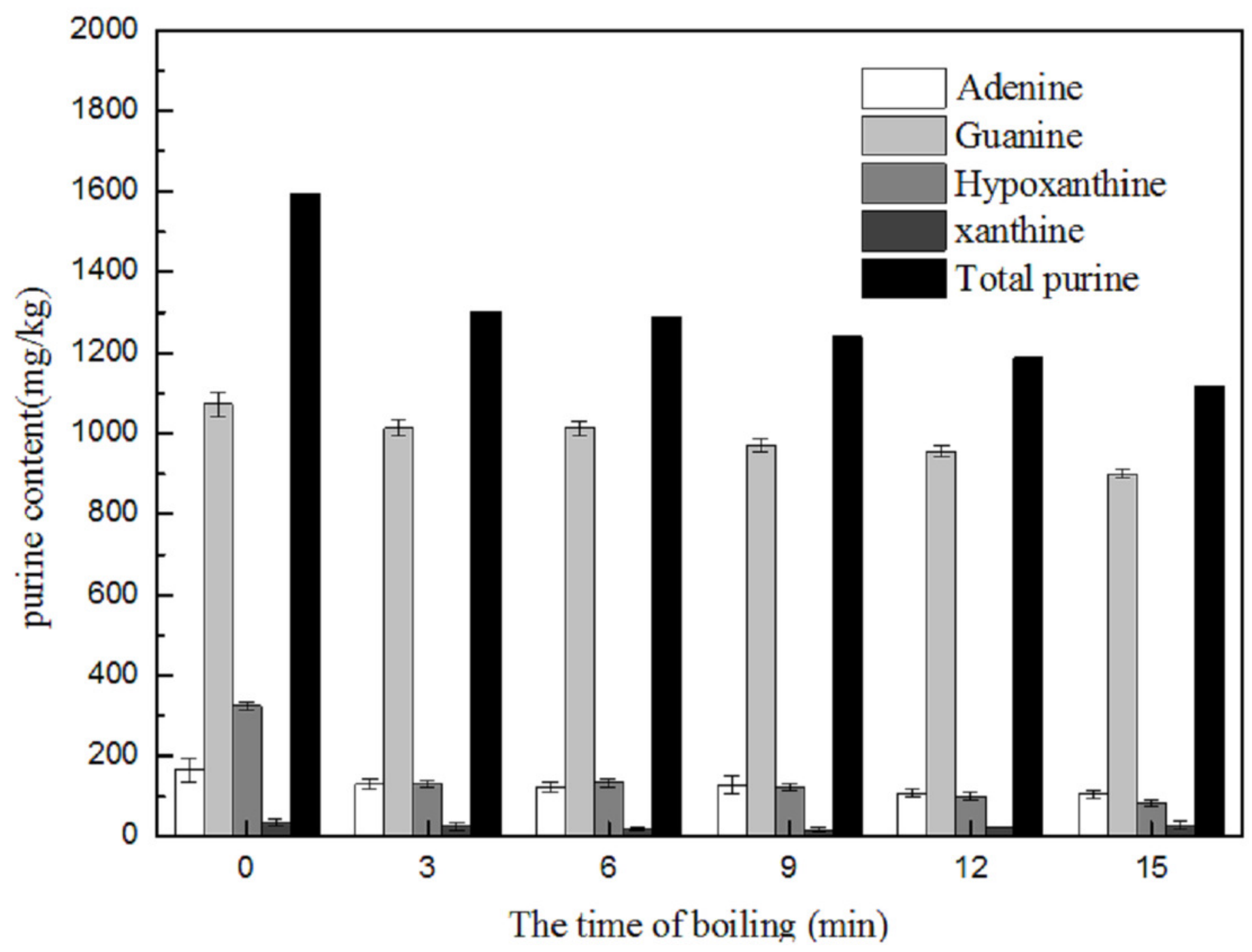


Figure 9

Effect of boiling on the purine contents in boiling liquid

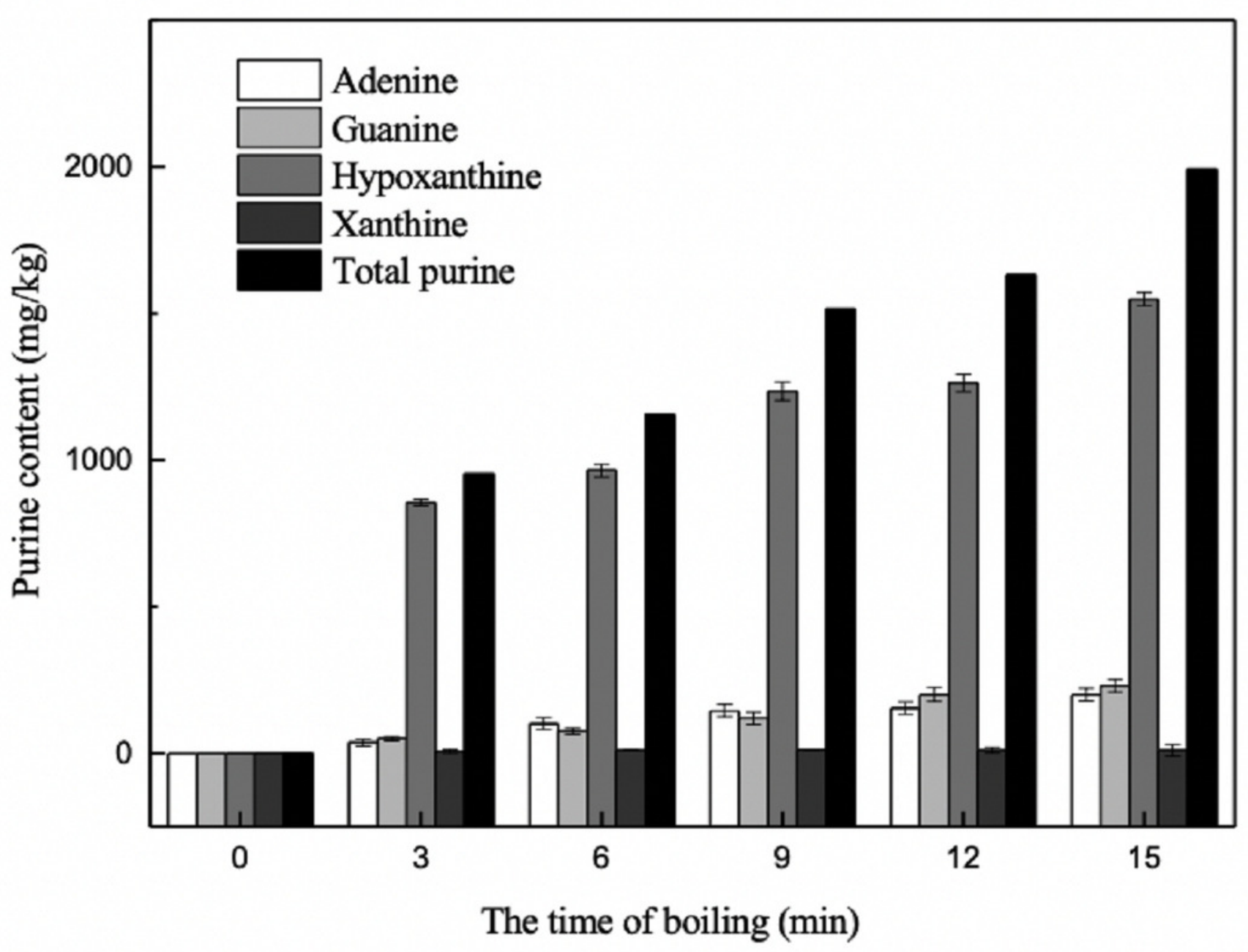




\section{Table $\mathbf{1}$ (on next page)}

Experimental variables and their levels used in the Plackett-Burman design of mix-acid method 
1 Table 1. Experimental variables and their levels used in the Plackett-Burman design of mix-acid

2 method

\begin{tabular}{|c|c|c|c|c|}
\hline \multicolumn{3}{|c|}{ Variables } & \multicolumn{2}{|c|}{ Levels } \\
\hline Factor codes & Factor & Units & Low $(-1)$ & $\operatorname{High}(+1)$ \\
\hline A & The temperature of hydrolysis & ${ }^{\circ} \mathrm{C}$ & 80 & 100 \\
\hline $\mathrm{B}$ & Liquid-Solid ratio & $\mathrm{ml} / \mathrm{g}$ & 20 & 40 \\
\hline $\mathrm{C}$ & The concentration of FA & $\%$ & 75 & 85 \\
\hline $\mathrm{D}$ & The concentration of TFA & $\%$ & 80 & 90 \\
\hline $\mathrm{E}$ & The time of sample hydrolysis & $\min$ & 5 & 15 \\
\hline
\end{tabular}

3 


\section{Table 2 (on next page)}

Levels of independent variables for Box-Behnken design experiment

(a) Experimental variables and their levels used in the BBD for PCA method. (b) Experimental variables and their levels used in the BBD for mix-acid method 


\begin{tabular}{|c|c|c|c|c|c|}
\hline \multicolumn{3}{|c|}{ Variables } & \multicolumn{3}{|c|}{ Levels } \\
\hline Factor codes & Name & Units & Low $(-1)$ & $(0)$ & High $(+1)$ \\
\hline A & The concentration of PCA & $\%$ & 70 & 80 & 90 \\
\hline B & Hydrolysis temperature & ${ }^{\circ} \mathrm{C}$ & 70 & 80 & 90 \\
\hline $\mathrm{C}$ & The time of sample hydrolysis & $\min$ & 50 & 55 & 60 \\
\hline $\mathrm{D}$ & Liquid-solid ratio & $\mathrm{ml} / \mathrm{g}$ & 50 & 60 & 70 \\
\hline
\end{tabular}

3

\begin{tabular}{|c|c|c|c|c|c|}
\hline \multicolumn{3}{|c|}{ Variables } & \multicolumn{3}{|c|}{ Levels } \\
\hline Factor codes & Name & Units & Low $(-1)$ & (0) & High $(+1)$ \\
\hline A & Hydrolysis temperature & ${ }^{\circ} \mathrm{C}$ & 80 & 90 & 100 \\
\hline B & The concentration of TFA & $\%$ & 80 & 85 & 90 \\
\hline $\mathrm{C}$ & The time of sample hydrolysis & $\min$ & 5 & 10 & 15 \\
\hline
\end{tabular}

5 (a) Experimental variables and their levels used in the BBD for PCA method. (b) Experimental variables and their levels used in 6 the BBD for mix-acid method 
Table 3 (on next page)

The results of PBD in the screening experiment 


\begin{tabular}{|c|c|c|c|c|c|c|c|}
\hline Score & Sum of Squares & Contribution & $\mathrm{df}$ & Mean Square & F-Value & $p$-value & \\
\hline Model & 24.940 & & 5 & 4.990 & 18.760 & 0.0013 & significant \\
\hline A-Hydrolysis temperature & 9.670 & 36.420 & 1 & 9.670 & 36.360 & 0.0009 & significant \\
\hline B-Liquid-solid ratio & 0.042 & 0.160 & 1 & 0.042 & 0.160 & 0.7047 & \\
\hline C-FA concentration & 0.810 & 3.040 & 1 & 0.810 & 3.030 & 0.1323 & \\
\hline D-TFA concentration & 4.140 & 15.610 & 1 & 4.140 & 15.580 & 0.0076 & significant \\
\hline E-Hydrolysis time & 10.290 & 38.760 & 1 & 10.290 & 38.690 & 0.0008 & significant \\
\hline Residual & 1.600 & & 6 & 0.270 & & & \\
\hline Cor Toal & 26.540 & & 11 & & & & \\
\hline
\end{tabular}

2

3

4

5

6 


\section{Table 4 (on next page)}

Analysis of variance for the experimental results of the Box- Behnken design in PCA method 
1 Table 4. Analysis of variance for the experimental results of the Box- Behnken design in PCA method

\begin{tabular}{|c|c|c|c|c|c|c|}
\hline Source & Sum of quares & df & Mean square & F-value & $p$-value & \\
\hline Model & 59.330 & 14 & 4.240 & 18.890 & $<0.0001$ & significant \\
\hline A-PCA concentration & 2.660 & 1 & 2.660 & 11.860 & 0.0040 & significant \\
\hline B-Hydrolysis temperature & 0.048 & 1 & 0.048 & 0.210 & 0.6504 & \\
\hline C-Sample hydrolysis time & 0.860 & 1 & 0.860 & 3.830 & 0.0707 & \\
\hline D-Liquie-Solid ratio & 1.410 & 1 & 1.410 & 6.300 & 0.0249 & significant \\
\hline $\mathrm{AB}$ & 0.029 & 1 & 0.029 & 0.130 & 0.7250 & \\
\hline $\mathrm{AC}$ & 1.090 & 1 & 1.090 & 4.870 & 0.0446 & significant \\
\hline $\mathrm{AD}$ & 0.500 & 1 & 0.500 & 2.250 & 0.1561 & \\
\hline $\mathrm{BC}$ & 0.0009 & 1 & 0.0009 & 0.004 & 0.9504 & \\
\hline $\mathrm{BD}$ & 0.032 & 1 & 0.032 & 0.140 & 0.7096 & \\
\hline $\mathrm{CD}$ & 0.710 & 1 & 0.710 & 3.140 & 0.0979 & \\
\hline $\mathrm{A}^{2}$ & 47.710 & 1 & 47.710 & 212.660 & $<0.0001$ & significant \\
\hline $\mathrm{B}^{2}$ & 2.920 & 1 & 2.920 & 13.010 & 0.0029 & significant \\
\hline
\end{tabular}




\begin{tabular}{|c|c|c|c|c|c|c|}
\hline $\mathrm{C}^{2}$ & 6.610 & 1 & 6.610 & 29.470 & $<0.0001$ & significant \\
\hline $\mathrm{D}^{2}$ & 0.000016 & 1 & 0.000016 & 0.00007 & 0.9933 & \\
\hline Residual & 3.140 & 14 & 0.220 & & & \\
\hline Lack of fit & 2.610 & 10 & 0.260 & 1.980 & 0.2661 & insignificant \\
\hline Pure error & 0.530 & 4 & 0.130 & & & \\
\hline Cor total & 62.470 & 28 & & & & \\
\hline
\end{tabular}

3

4 


\section{Table 5(on next page)}

Analysis of variance for the experimental results of the Box- Behnken design in mix-acid method 
1 Table 5. Analysis of variance for the experimental results of the Box- Behnken design in mix-

2 acid method

\begin{tabular}{|c|c|c|c|c|c|c|}
\hline Source & Sum of Squares & $\mathrm{df}$ & Mean square & F-value & $p$-value & \\
\hline Model & 57.05 & 9 & 6.34 & 40.10 & $<0.0001$ & significant \\
\hline A-Hydrolysis temperature & 1.23 & 1 & 1.23 & 7.80 & 0.0268 & significant \\
\hline B-TFA concentration & 2.00 & 1 & 2.00 & 12.65 & 0.0093 & significant \\
\hline C-Sample hydrolysis time & 0.99 & 1 & 0.99 & 6.29 & 0.0405 & significant \\
\hline $\mathrm{AB}$ & 7.08 & 1 & 7.08 & 44.76 & 0.0003 & significant \\
\hline $\mathrm{AC}$ & 2.02 & 1 & 2.02 & 12.75 & 0.0091 & significant \\
\hline $\mathrm{BC}$ & 2.40 & 1 & 2.40 & 15.20 & 0.0059 & significant \\
\hline $\mathrm{A}^{2}$ & 29.56 & 1 & 29.56 & 186.97 & $<0.0001$ & significant \\
\hline $\mathrm{B}^{2}$ & 2.21 & 1 & 2.21 & 13.98 & 0.0073 & significant \\
\hline $\mathrm{C}^{2}$ & 6.47 & 1 & 6.47 & 40.92 & 0.0004 & significant \\
\hline Residual & 1.11 & 7 & 0.16 & & & \\
\hline Lack of fit & 0.34 & 3 & 0.11 & 0.59 & 0.6523 & insignificant \\
\hline Pure error & 0.77 & 4 & 0.19 & & & \\
\hline
\end{tabular}




\begin{tabular}{ll}
\hline Cor total & 58.16 \\
\end{tabular}

3

4 


\section{Table 6(on next page)}

Optimum conditions, Adjust conditions, predicted and experimental value of response at that condition

(a) validation test of PCA purine extraction method.

${ }^{1} \mathrm{~A}$-PCA concentration ${ }^{2} \mathrm{~B}$-Hydrolysis temperature ${ }^{3} \mathrm{C}$-Hydrolysis time ${ }^{4} \mathrm{D}$-Liquid-solid ratio

(b) validation test of mix-acid purine extraction method.

${ }^{\mathrm{a} A}$-Hydrolysis temperature ${ }^{\mathrm{b}} \mathrm{B}-\mathrm{TFA}$ concentration ${ }^{\mathrm{C}} \mathrm{C}$-The time of sample hydrolysis ${ }^{\mathrm{d}} \mathrm{D}-\mathrm{FA}$ concentration ${ }^{\mathrm{e}} \mathrm{E}-$ Liquid-soild ratio 
1 Table 6. Optimum conditions, Adjust conditions, predicted and experimental value of response at

2

3 that condition

(a)

\begin{tabular}{|c|c|c|c|c|c|c|}
\hline & \multicolumn{4}{|c|}{ Conditions } & \multicolumn{2}{|c|}{ Total purine extraction yield } \\
\hline & ${ }^{1} \mathrm{~A}$ & ${ }^{2} \mathrm{~B}$ & ${ }^{3} \mathrm{C}$ & ${ }^{4} \mathrm{D}$ & Predicted & Experimental \\
\hline Optimum & 80.97 & 79.78 & 54.20 & $50.78: 1$ & 86.15 & \\
\hline Actual operating & 80.00 & 80.00 & 55.00 & $50.00: 1$ & & $83.75 \pm 2.65$ \\
\hline
\end{tabular}

$4 \quad{ }^{1} \mathrm{~A}-\mathrm{PCA}$ concentration ${ }^{2} \mathrm{~B}$-Hydrolysis temperature ${ }^{3} \mathrm{C}$-Hydrolysis time ${ }^{4} \mathrm{D}$-Liquid-solid ratio

5

(b)

\begin{tabular}{|c|c|c|c|c|c|c|c|}
\hline & \multicolumn{5}{|c|}{ Conditions } & \multicolumn{2}{|c|}{ Total purine extraction yield } \\
\hline & ${ }^{\mathrm{a}} \mathrm{A}$ & ${ }^{\mathrm{b}} \mathrm{B}$ & ${ }^{\mathrm{c}} \mathrm{C}$ & ${ }^{\mathrm{d}} \mathrm{D}$ & ${ }^{\mathrm{e}} \mathrm{E}$ & Predicted & Experimental \\
\hline Optimum & 91.83 & 88.00 & 9.43 & 80.00 & $30: 1$ & 104.51 & \\
\hline Actual operating & 90.00 & 90.00 & 10.00 & 80.00 & $30: 1$ & & $103.94 \pm 3.85$ \\
\hline
\end{tabular}

$6{ }^{\mathrm{a} A} \mathrm{~A}-\mathrm{Hydrolysis}$ temperature ${ }^{\mathrm{b}} \mathrm{B}-\mathrm{TFA}$ concentration ${ }^{\mathrm{c}} \mathrm{C}$-The time of sample hydrolysis ${ }^{\mathrm{d} D} \mathrm{D}-\mathrm{FA}$ concentration ${ }^{\mathrm{e}} \mathrm{E}$-Liquid-soild ratio

7 (a) validation test of PCA purine extraction method. (b) validation test of mix-acid purine extraction method 


\section{Table 7(on next page) \\ Linear relation results $(n=3)$}

${ }^{a}$ Variables: $y$, peak area $(\mathrm{mV}) ; \mathrm{x}$, concentration of each analyte $(\mathrm{mg} / \mathrm{L})$ 
Table 7. Linear relation results $(n=3)$

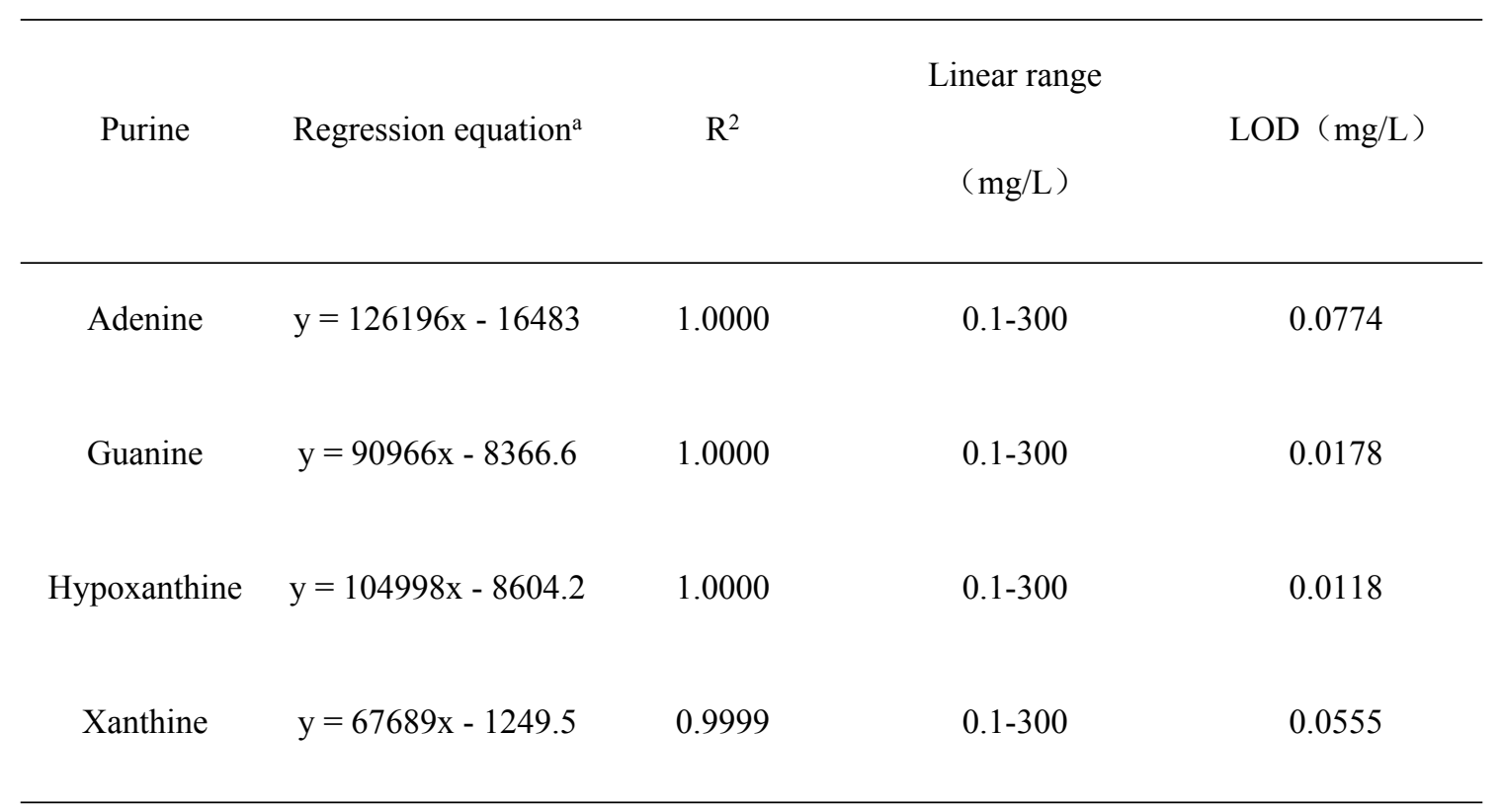

2 aVariables: y, peak area $(\mathrm{mV}) ; \mathrm{x}$, concentration of each analyte $(\mathrm{mg} / \mathrm{L})$ 


\section{Table 8 (on next page)}

Precision, repeatability, and recovery results $(n=6)$

${ }^{\text {a }}$ Expressed as RSD by mixed purine base standards solution repeated six times.

${ }^{\mathrm{b}}$ Expressed as RSD by Scophthalmus maximus (dorsal muscles) repeated six times.

${ }^{\mathrm{c}}$ Average of recoveries at three spiked levels. 
Table 8. Precision, repeatability, and recovery results $(n=6)$

\begin{tabular}{cccc}
\hline Purine & Precision $(\%)^{\mathrm{a}}$ & Repeatability $(\%)^{\mathrm{b}}$ & Recovery mean (\%) $^{\mathrm{c}}$ \\
\hline Adenine & 0.13 & 1.32 & 95.31 \\
Guanine & 0.69 & 0.87 & 94.90 \\
Hypoxanthine & 0.02 & 0.83 & 104.51 \\
Xanthine & 0.06 & 1.77 & 95.48 \\
\hline
\end{tabular}

aExpressed as RSD by mixed purine base standards solution repeated six times.

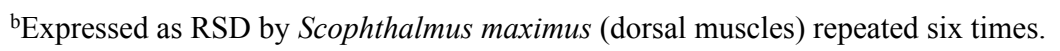




\section{Table 9 (on next page)}

Purine content in different parts of marine fish (mean \pm S.D.)

${ }^{\text {aTotal purine }}=$ Adenine + Guanine + Hypoxanthine + Xanthine

${ }^{b}$ not detected 


\begin{tabular}{|c|c|c|c|c|c|}
\hline Sample & Adenine & Guanine & Hypoxanthine & Xanthine & Total \\
\hline Scophthalmus maximus (dorsal muscles) & $127.50 \pm 1.32$ & $143.51 \pm 4.52$ & $820.71 \pm 20.57$ & $96.39 \pm 5.33$ & 1188.12 \\
\hline Scophthalmus maximus (abdominal muscles) & $135.33 \pm 2.74$ & $155.33 \pm 2.72$ & $920.61 \pm 2.63$ & $91.55 \pm 1.85$ & 1302.82 \\
\hline Scophthalmus maximus (skin) & $247.04 \pm 4.57$ & $1190.03 \pm 24.06$ & $206.01 \pm 5.55$ & $42.65 \pm 0.92$ & 1685.73 \\
\hline Scophthalmus maximus (viscera) & $378.05 \pm 3.16$ & $467.58 \pm 13.23$ & $256.01 \pm 16.76$ & $114.72 \pm 8.87$ & 1216.36 \\
\hline Scophthalmus maximus (eyes) & $6.55 \pm 0.00$ & $3820.77 \pm 28.33$ & $117.39 \pm 0.53$ & ${ }_{-}^{\mathrm{b}}$ & 3944.71 \\
\hline Scomberomorus niphonius (dorsal muscles) & $121.17 \pm 0.34$ & $135.86 \pm 7.76$ & $704.17 \pm 23.14$ & $22.32 \pm 3.70$ & 983.53 \\
\hline \multicolumn{6}{|l|}{ Scomberomorus niphonius (abdominal } \\
\hline & $148.01 \pm 2.42$ & $177.65 \pm 15.17$ & $651.59 \pm 7.80$ & $17.66 \pm 0.16$ & 994.91 \\
\hline \multicolumn{6}{|l|}{ muscles) } \\
\hline Scomberomorus niphonius (skin) & $194.95 \pm 7.09$ & $588.67 \pm 26.14$ & $314.62 \pm 4.93$ & $23.29 \pm 1.34$ & 1121.53 \\
\hline Scomberomorus niphonius (viscera) & $326.38 \pm 0.14$ & $822.00 \pm 9.37$ & $1015.87 \pm 1.48$ & $498.97 \pm 0.44$ & 2663.22 \\
\hline Scomberomorus niphonius (eyes) & $140.63 \pm 2.68$ & $1636.54 \pm 69.73$ & $255.58 \pm 2.82$ & $50.29 \pm 0.80$ & 2083.04 \\
\hline Pleuronectiformes (dorsal muscles) & $110.85 \pm 4.85$ & $109.43 \pm 3.42$ & $503.69 \pm 18.61$ & $70.14 \pm 2.12$ & 794.11 \\
\hline Pleuronectiformes (abdominal muscles) & $157.77 \pm 2.22$ & $398.17 \pm 1.10$ & $645.52 \pm 8.28$ & $7.39 \pm 0.41$ & 1208.85 \\
\hline Pleuronectiformes (skin) & $83.70 \pm 4.77$ & $234.05 \pm 19.29$ & $385.25 \pm 9.18$ & $2.31 \pm 0.13$ & 705.31 \\
\hline
\end{tabular}


Pleuronectiformes (viscera)

Pleuronectiformes (eyes)

Sea catfish (dorsal muscles)

Sea catfish (abdominal muscles)

Sea catfish (skin)

Sea catfish (viscera)

Sea catfish (eyes)

Sardinella (dorsal muscles)

Sardinella (abdominal muscles)

Sardinella (skin)

Sardinella (viscera)

Sardinella (eyes)

Sphyraena (dorsal muscles)

Sphyraena (abdominal muscles)

Sphyraena (skin)

Sphyraena (viscera)
$673.41 \pm 8.00$

$980.73 \pm 9.34$

$157.62 \pm 0.56$

$1390.48 \pm 5.31$

$107.96 \pm 0.46$

$110.48 \pm 0.13$

$84.53 \pm 0.78$

$101.70 \pm 0.26$

$244.51 \pm 3.73$

$463.46 \pm 13.39$

$496.76 \pm 0.47$

$482.56 \pm 0.09$

$305.94 \pm 0.04$

$1.89 \pm 0.01$

1287.15

$56.56 \pm 0.01$

$807.51 \pm 0.19$

$114.82 \pm 0.05$

$31.73+0.04$

1010.64

$88.30 \pm 0.05$

$62.15 \pm 0.08$

$486.70 \pm 0.80$

$37.47 \pm 0.01$

674.62

$136.73 \pm 0.15$

$106.22 \pm 0.06$

$835.42 \pm 0.78$

$52.04 \pm 0.15 \quad 1130.41$

$118.90 \pm 0.12 \quad 1100.16 \pm 0.35$

$918.66 \pm 2.01$

$121.20 \pm 0.05$

2258.91

$429.03 \pm 4.72$

$607.65 \pm 2.39$

$549.02 \pm 2.34$

$257.57 \pm 0.46$

1843.26

$69.94 \pm 0.35$

$1156.23 \pm 0.52$

$161.82 \pm 0.03$

$56.40 \pm 0.05$

1444.39

$110.57 \pm 0.24$

$84.06 \pm 0.84$

$715.71 \pm 0.49$

$8.85 \pm 0.33 \quad 919.19$

$101.74 \pm 0.02$

$314.09 \pm 0.70$

$656.65 \pm 3.02$

$185.27 \pm 0.10 \quad 1257.75$

$130.45 \pm 0.01 \quad 3651.71 \pm 0.95$

$567.29 \pm 0.23$

$69.19 \pm 0.26$

4418.64

$722.00 \pm 2.58 \quad 952.23 \pm 12.49$

$901.25 \pm 0.33$

$144.24 \pm 0.41 \quad 2719.72$ 


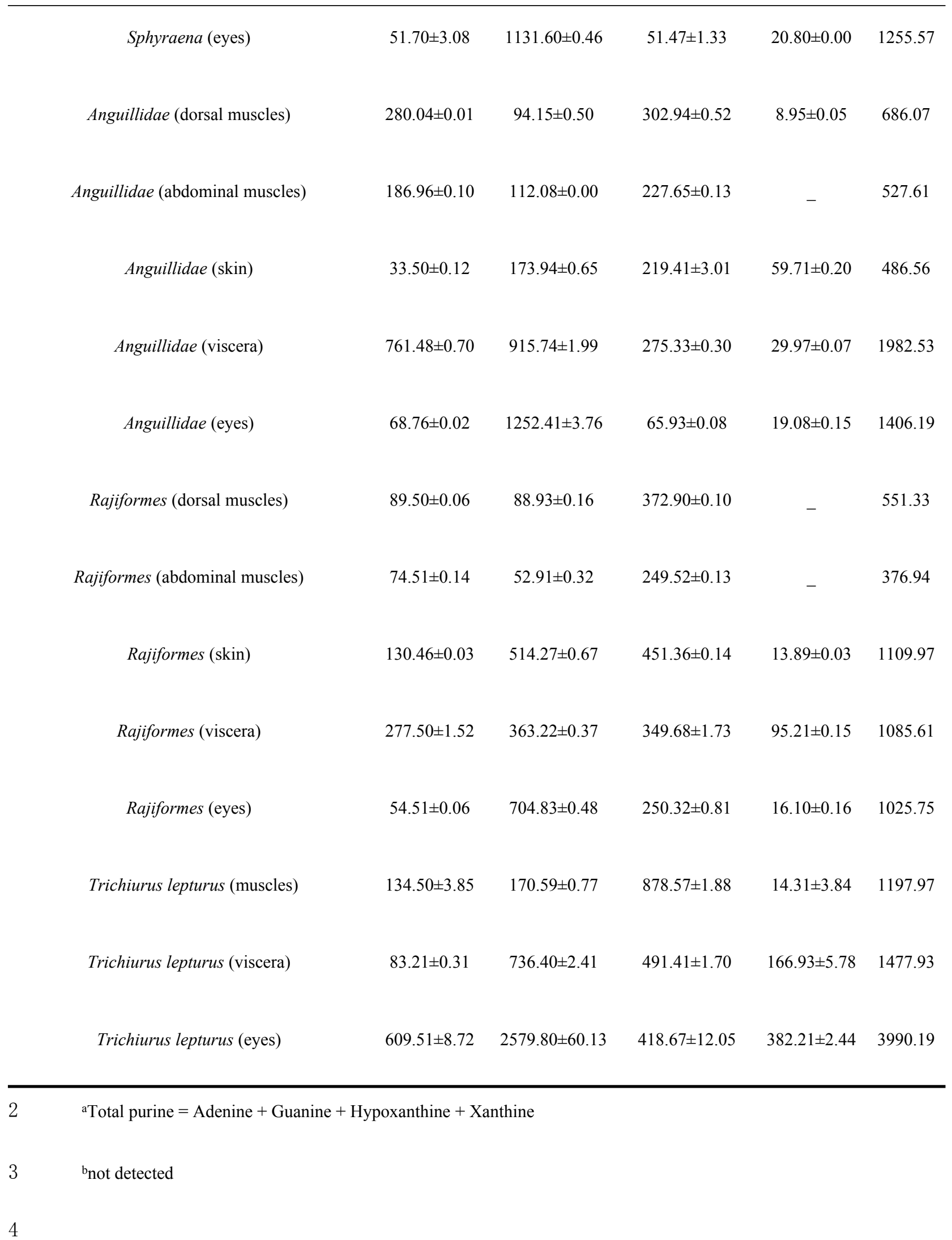


